\title{
The Spectacular Rotation of Earth About the Main Axis
}

\section{Charles Edward Ng'hwaya Masule}

Institute of Mechanical Engineering, Mechanical Process Engineering and Environmental Technology, Dresden University of Technology, Dresden, Germany

\section{Email address:}

nghwaya@yahoo.co.uk (C. E. Ng’hwaya Masule), c.e.masule@gmail.com (C. E. Ng'hwaya Masule)

\section{To cite this article:}

Charles Edward Ng'hwaya Masule. The Spectacular Rotation of Earth About the Main Axis. American Journal of Astronomy and Astrophysics. Vol. 3, No. 6, 2015, pp. 93-117. doi: 10.11648/j.ajaa.20150306.12

\begin{abstract}
The fact that the orbit of Earth and the other planets in the Solar system are elliptic had been posing a mystery in science since creation. Also, explanation had been missing as to: the cause and the mysterious behavior of high and low tide as well as to the cause of Earth quakes. In this publication, it had been found that Earth rotates about the Main axis (alias the Geometric North-South axis) in a to-and-from motion with a period of about 365.24 days keeping the locus of its Obliquity fixed. All planets and natural satellites in the solar system are inclined to follow an elliptic trajectory because of the trait of the massive object in the gravitational relationship to exercise - by firing - a unilateral force, the robotics force, of decaying nature which causes the less massive partner not only to progressively change the plane of its trajectory but also causes the path of the less massive partner to be elliptic. The robotics force is responsible for the striking of quakes as well as for the happening and behavior of low and high tides. The robotics force will be represented by a sinusoidal component in the Newton's law gravitation: $F_{G}=G \frac{M_{E} M_{S}}{\bar{R}^{2}}\left(1+\varepsilon \times \sin ^{n} \theta+\left(\chi \times e^{\cos \theta}\right)\right)$ The universe keeps an eye to its celestial objects by enforcing the law of the universe: $\sum_{k=0}^{k=n} \sum_{j=0}^{j=m}\left({ }_{p} F_{G}\right)_{k} \times\left({ }_{s} F_{G}\right)_{j}=$ const $=\lambda_{U}$.

Keywords: Day and Night, Earth's Ecliptic, Earth's Ghost Forces of Rotation, Earth's Rotation, Equinoxes, Solstice, Newton's Law of Gravitation, Law of the Universe, Robotics Force, Automation of the Universe, Earth Quakes, Syzygy, Syzygy Events, Moon Eclipse, Eclipses, Obliquity, Albedo, Main Axis, Geometric North-South Axis
\end{abstract}

\section{Introduction}

It is settled fact in astrophysics and astronomy that planet Earth orbits the Sun in a heliocentric orbit with a period of about 365.24 days [1]. Besides orbiting, it is undisputable that Earth rotates about its axis to make day and night with a period of about 24 hours [1]. To be specific and avoid confusions, Earth rotates about the Obliquity axis to make day and night.

Whereas it is getting closer to saying that Earth and some of the planets of the Solar system exhibit the obliqui-sliding property whereby the locus of the Obliquity axis remains constant but the planet rotates about the main axis in a toand-from fusion; Venus, Uranus and Pluto - with Obliquity angles greater than 90 degrees - seem to exhibit the obliquihovering property whereby the locus of the Obliquity axis changes in the course of planets rotation about the Main axis. For planet Earth the Main axis (alias the Geometric NorthSouth axis or the Ghost axis or the Climate Turbo axis) is believed to be perpendicular to the orbital plane [1]. A debate is open as to a possibility of a planet to behave obliqui-static whereby there exists no rotation about any of its axes or behave obliqui-dynamic whereby there exists rotation about the Obliquity axis but no rotation about the Main axis.

Whereas the Equator experiences about 12 hours of day to 12 hours of night around the year as a matter of settled fact, the poles and the latitudes closer to them experience days when the Sun never sets at certain times of the year and also experience days when the Sun never rises. Latitudes closer to the dark latitudes experience much shorter and lower Sun tracks across the sky in the winter than in the summer.

It is debatable as to why the event of 12 hours of day to 12 hours of night does not happen at the same time across latitudes on Earth? Instead, the event progresses from the Equator towards the North Pole in the course of time approaching the March Equinox; and towards the South Pole in the course of time approaching the September Equinox.

Although the Earth's rotation about the Obliquity axis may 
be considered to mount some tension on the Earth crust that possibly lead to the quaking of Earth, it would perhaps make more sense in terms of tension on the Earth crust if another force or a component thereof would exist to act in a counter direction to the force causing the rotation about the Obliquity axis.

\section{Geometry of Day and Night}

At any time $t$, the geometric half of the globe is illuminated whereas the other half is dark because of the globe's own shadow (fig 1). The Earth's angular displacement in radians as a function of time from a reference position $q_{0}$ is given by [1]:

$$
q(t)=q_{0}+\omega t
$$

Where: $q_{0}$ is a reference position [radians]

$\omega$ is the angular velocity $\left[s^{-1}\right]$

$t$ is the elapsed time $[S]$

In terms of Julian days, the Earth's angular displacement in degrees with reference to January $0.5,1900$ is given by [2]:

$$
q(t)=279.69667778+0.985647335 t
$$

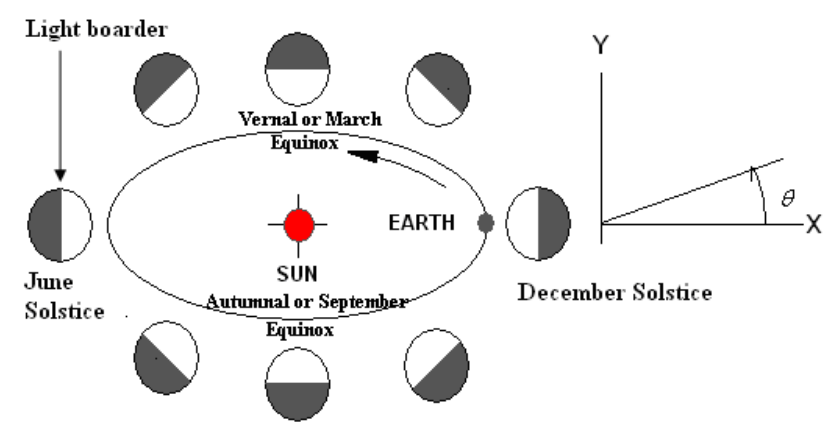

Fig. 1. Schematic Top View of Earth Orbiting the Sun.
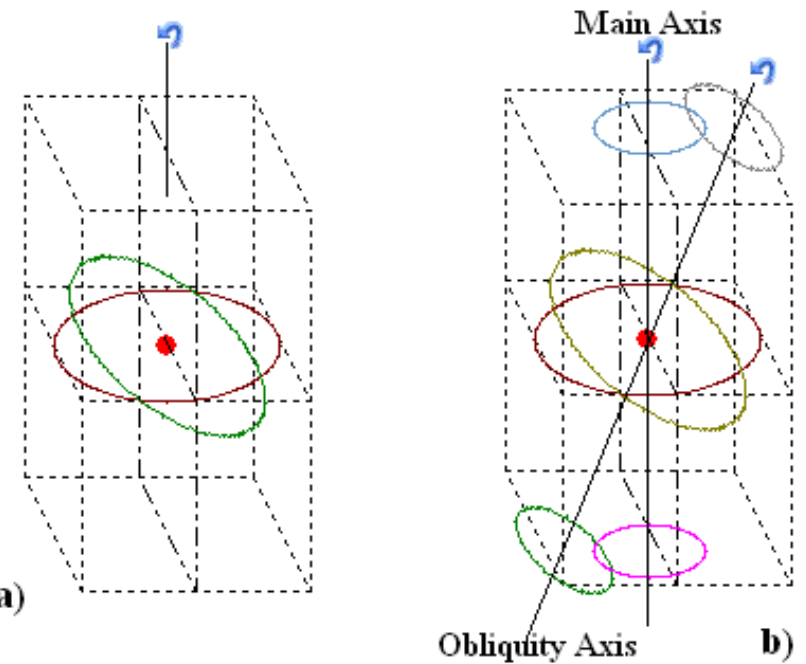

Fig. 2. Isometric View of the Equatorial Plane Relative to the Horizontal Plane.

\section{The Equator Exception}

Because the centre of the Earth's Equatorial plane geometrically coincides with the Earth's horizontal plane at the center of the globe (fig. 2), the day time will approximately be equal to the night time at any time $t$ at the Equator. The respective planes on the globe will geometrically be cut by the light boarder into two halves. If Earth would not rotate about the Main axis, the moment of 12 hours day to 12 hours night would take place at the same time through out the globe when the light boarder would be cutting through the two axes in fig. 2 (b). Say: if the obliquity axis would be coinciding with the Solstices or the $\mathrm{x}$-axis in fig. 1, the said moment of 12 hours day to 12 hours night would happen at the Equinoxes.

\section{The Geometry of the Rotation About the Main Axis}

The following assumptions are worth:

1) Earth is a perfect sphere

2) The location of the Obliquity axis relative to the $x$-axis, $\phi_{x}$, is $-23.4^{\circ}$ (fig. 3)

3) The location of the Obliquity axis relative to the y-axis, $\phi_{y}$, is $23.4^{\circ}[1]$

4) The North Pole likewise the South Pole rotates along the obliquity circle in a to- and-from fusion

5) The light border never crosses the North Pole or South Pole at the Obliquity locus

6) The North Pole coincides with the fake North Pole at the event of the September Equinox

7) The rotation about the Main axis makes a u-turn at the Equinoxes

8) The period of rotation about the Main Axis is about 365.24 days

\subsection{The Geometry at the December Solstice}
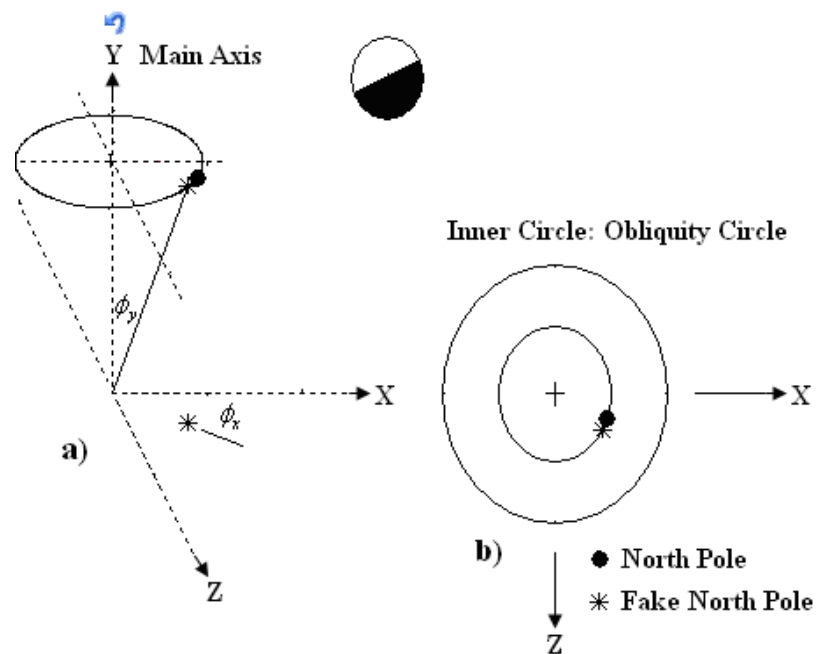

Fig. 3. Location of the North Pole after Sep. Equinox: a) in Isometric View and b) on Top View. 
It is assumed to be a few days after the September Equinox. The North Pole is already dark and has just left the point of the fake North Pole (fig. 3).

As Earth moves towards the December Solstice, the rotation about the Main Axis will be turning the globe to make the North Pole to approach the December Solstice as well (fig. 3 and 4). Part of the Northern Hemisphere, the Arctic Circle, is completely dark at the December Solstice.
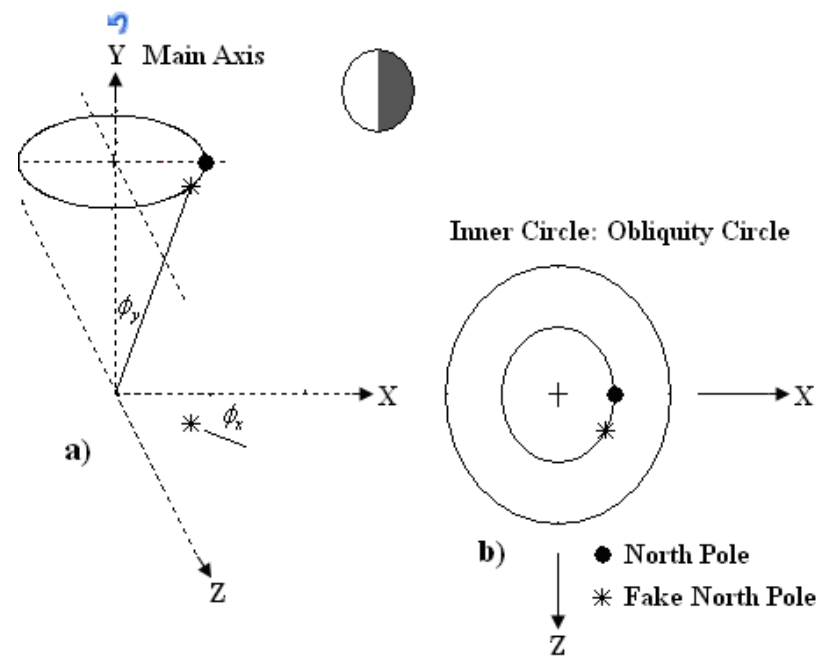

Fig. 4. Location of the North Pole at the Dec. Solstice: a) in Isometric View and b) on Top View.

\subsection{The Geometry at the March Equinox}

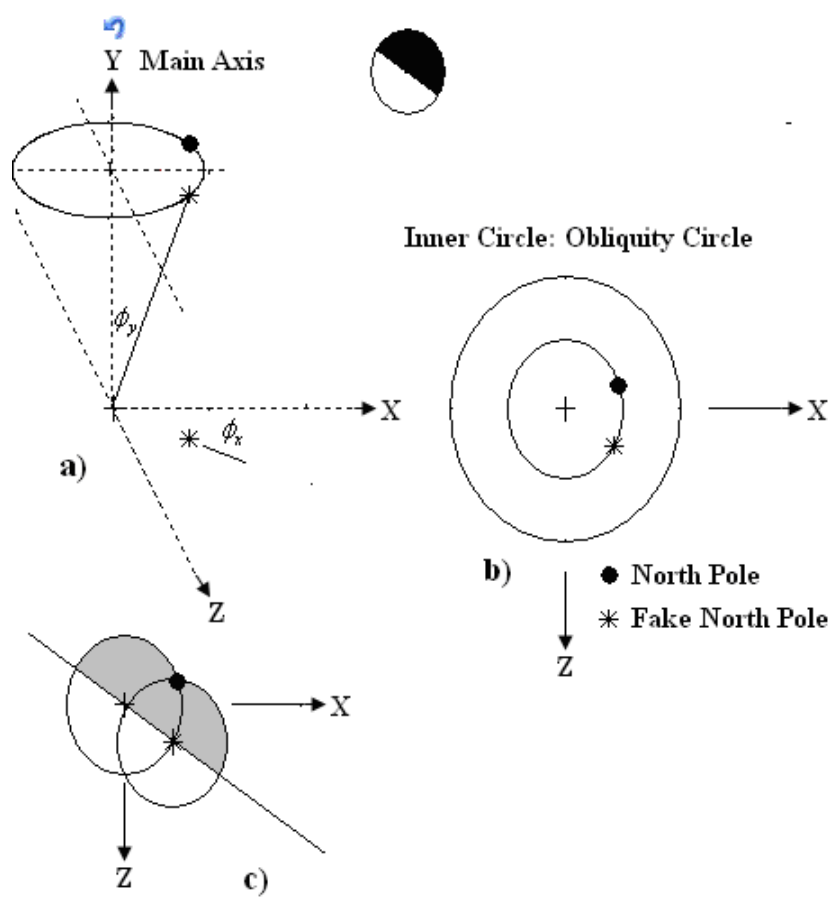

Fig. 5. Location of the North Pole before the March Equinox: a) in Isometric View and b) on Top View c) Day Hours versus Night Hours.

It can geometrically be shown by drawing a circle of a diameter equal to the distance between the fake North Pole and the North Pole that the North Pole will already have attained the moment of 12 hours day to 12 hours night before the March Equinox (Fig. 5) and that it will be illuminated for more than 12 hours a day at the March Equinox (Fig. 6). The rotation about the Main axis makes a u-turn.

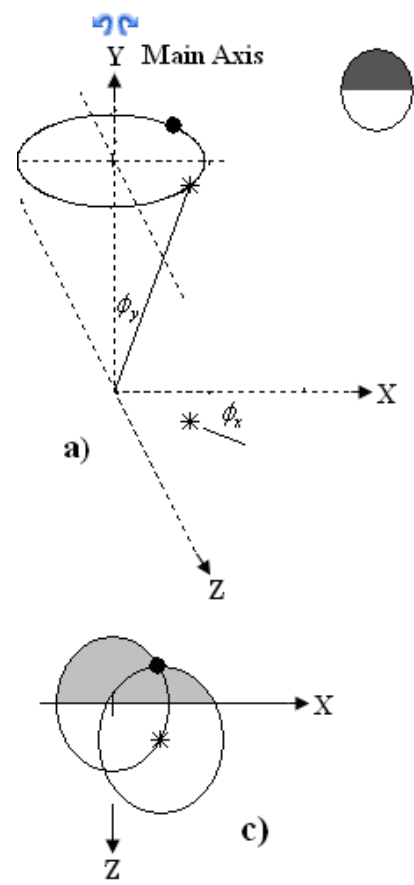

Inner Circle: Obliquity Circle

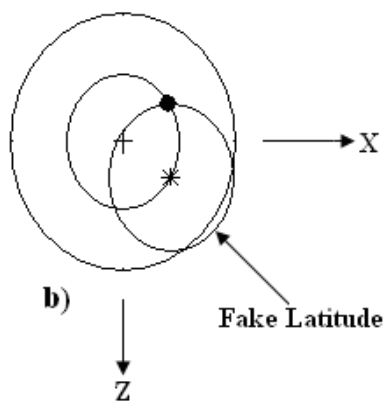

North Pole

* Fake North Pole

Fig. 6. Location of the North Pole at the March Equinox: a) in Isometric View and b) on Top View c) Day Hours versus Night Hours.

\subsection{The Geometry at the June Solstice}

Whereas the North Pole will be experiencing 24 hours of day, the South Pole will be experiencing 24 hours of night. The fake Poles marry the actual Poles at this point (fig. 7).
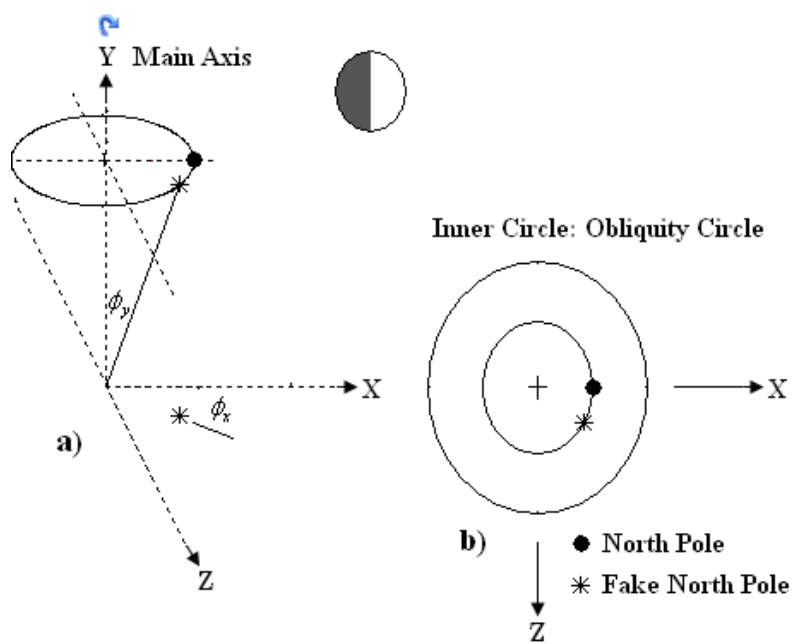

Fig. 7. Location of the North Pole at the June Solstice: a) in Isometric View and b) on Top View.

\subsection{The Geometry at the September Equinox}

The geometry at the September Equinox resembles that at the March Equinox with the exception that the description 
changes over to the Southern Hemisphere (fig. 8). The rotation about the Main axis makes a u-turn.

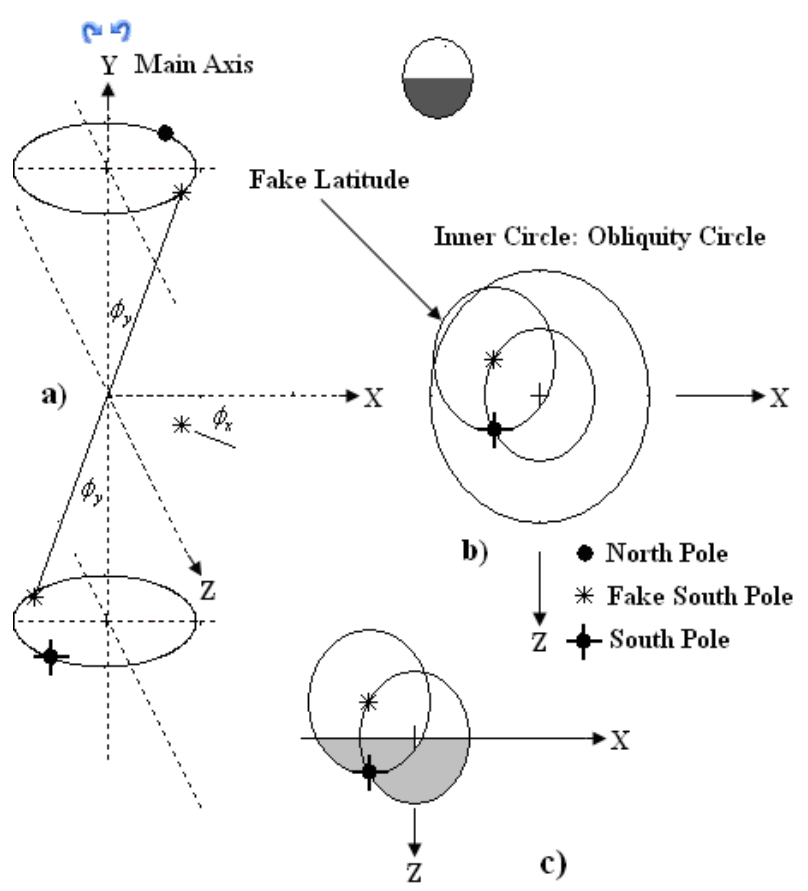

Fig. 8. Location of the South Pole at the September Equinox: a) in Isometric View and b) on Top View c) Day Hours versus Night Hours

\section{Modeling High Tides and Low Tides}

For the purpose of modeling, high tides and low tides can be assumed to be a result of a hydrostatic potential height $\Delta \mathrm{H}$ caused by gravitational forces in principle (fig. 9). This will mean that the potential flow will always be towards the lower side of the Equator or the Obliquity line at the Equator (fig. 9).

The hydrostatic potential from the Geometrical North will always have a mirror coming from the Geometrical South in the opposite direction and side (fig. 9). If Earth would not be rotating about the Main axis, moments of high tides and low tides at any particular longitude would remain the same in terms of time. Because of the Earth's rotation about the Main axis, tides are constant with respect to the Obliquity and fake longitudes but a traveling wave with respect to the real longitudes. The influence of the Moon's gravitational force on tides can be debated.

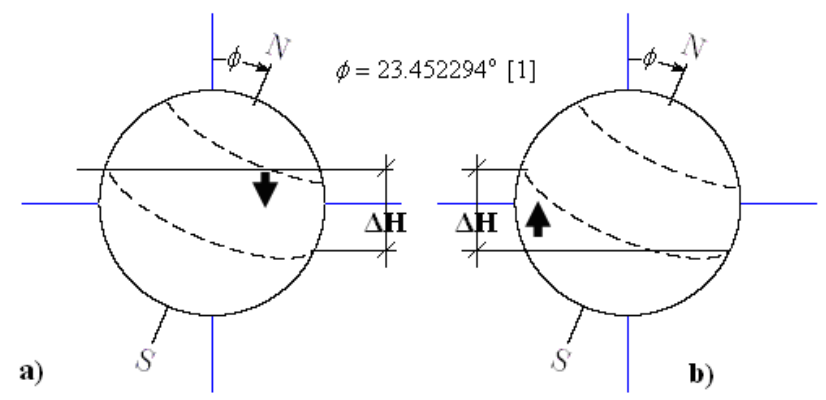

Fig. 9. Hydrostatic Potential Heights: a) From the Geometric North b) From the Geometric South.

\section{Newton's Law of Gravitation}

The force between the Sun and Earth is governed by the Newton's Law of Gravitation [1]:

$$
F_{G}=G \frac{M_{E} M_{S}}{R^{2}}
$$

Where: $F_{G}$ is the force between the two masses [N]

$G$ is the gravitational constant $\left[6.673 \times 10^{-11} \mathrm{~N} .(\mathrm{m} / \mathrm{kg})^{2}\right]$

$M_{E}$ is the mass of Earth [kg]

$M_{S}$ is the mass of the Sun [kg] [m]

$R$ is the distance between the centers of the two masses

\section{Discussion}

\subsection{High Tides and Low Tides}

High tide and low tide data prove that the time interval between the occurrences of two consecutive low tides as well as the time interval between the occurrences of two consecutive high tides at Tonga in the South Pacific Sea is about 25 hours (table A1 \& A2). It takes about 17 hours for the next high tide to arrive since the last low tide arrival which means 8 hours are needed to complete the cycle back to the arrival of a low tide (table A1 \& A2). These times of arrival of the tides manifest a convincing progressive positive shift of one hour with increasing days despite the somewhat long interval of one hour between the gauging at Tonga. If the hydrostatic potential driving the tides is to be assumed to be in line with the line of the gravitational relationship between Earth and the Moon, then the progressing increase in the time of arrival of the tides can be justified by the changing of the locus of the gravitational relationship because the locus of Moon is dynamic if Earth's locus could be reservedly be taken to be constant as it changes relatively slower in this context. But, the time interval between the arrival of high tides and the low tides is still to be discussed at a different point as it is taken for granted to be about 12 hours instead of 17 hours.

It is getting evident from table A1 that the locus of the hydraulic potential gradient driving the tides experiences a rotation of about $180^{\circ}$ - better call it a u-turn or a somersault - at around the first quarter and near the last quarter of the Moon which manifest itself in the difference of about 13 hours between the times of arrival of the new tide to the old tide. The response to this rotation is felt first as a high tide before the low tide response. In table A1, the response of the rotation has been marked by the underlined entries. What does this mean? Earth will launch fresh strongest pulls at around the first quarter and near the last quarter of the Moon. It also means that, the pull affecting the Earth's atmosphere and water bodies is an Earth's self-mounted pull - a sort of self-assaulting. It is as if there is a suction machine generating vacuum on the opposite side of the globe facing 
the moon (fig. 10). The rotation of the tidal wave also means that the surge of the pull is a unilateral decaying force in terms of magnitude and direction. The new strike will kill the last force to put the new force in place. There is however a lack of information to substantiate as to why the high tide arrival at Tonga will be recorded first before the low tide arrival (table A1, A2, A3, A4 and A5). A comparison of this phenomenon using data from different gauging stations was not undertaken.

The gravitational pull of the moon per se can be ruled out to be causing the tidal waves.

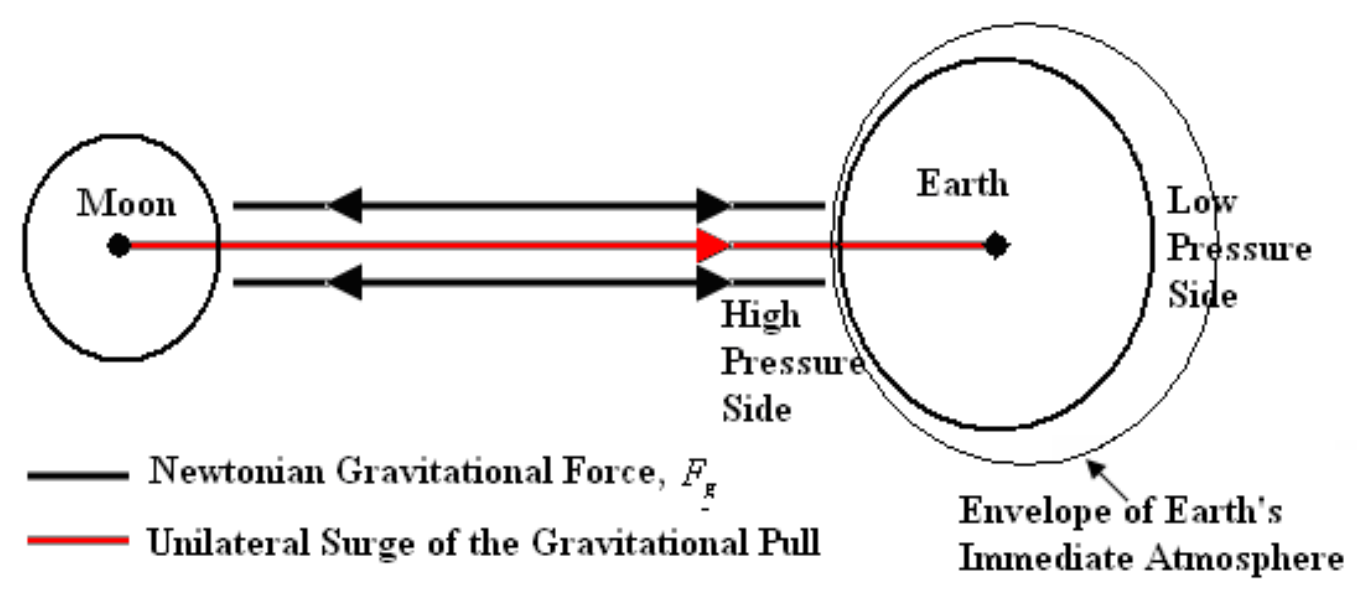

Fig. 10. Earth's Surge of Gravity Pull at the $1^{\text {st }}$ and Last Quarter of the Moon.

There are three influences to note as to the Earth's surge of gravitational pull:

- Earth's position in its elliptic trajectory: In table A1 there is a surge between January $06^{\text {th }}$ and $08^{\text {th }} 2014$ which is close to the $1^{\text {st }}$ quarter of the moon (fig. A1 a). The surge of February 2014 between $18^{\text {th }}$ and $21^{\text {st }}$ table A1 is between a full moon and the last quarter of the moon (fig. A1 b). The surge of March 2014 between $15^{\text {th }}$ and $19^{\text {th }}$ table A1 is centered at the full moon (fig. A2 a). The surge of September 2014 between $22^{\text {nd }}$ and $26^{\text {th }}$ in table A1 is centered at the new moon (fig. A2 b). The surge can therefore be said to be centered at the $1^{\text {st }}$ and last quarter of the moon.

- System errors: instabilities which seem to be caused by the system seem to be noted and rectified by the system itself. This is typical of a designed control system in automation engineering. Example: The instability of 2014 January between $22^{\text {nd }}$ and $26^{\text {th }}$ in table A1 as well as the instability 2015 February between $06^{\text {th }}$ and $09^{\text {th }}$ in table A2. Entries in bold italics depict this influence of system instability (table A1, A2, A3, A4 and A5).

- Syzygy events: a penumbral eclipse seems to have the effect of shifting the surge from mid way towards the $1^{\text {st }}$ and last quarter of the moon as in the surge of February 1998 between $14^{\text {th }}$ and $19^{\text {th }}$ in table A3. Syzygy events seem to have no effects in the months of the Equinoxes and the Solstices (table A4 and A5).

\subsection{Newton's Law of Gravitation and the Robotics Force}

Out of the facts established in section 7.1 as to the rotation of tidal waves, it can reasonably be taken to hold for any gravitational relationship in the solar system that the massive object will exercise a unilateral control force, the robotic force $F_{R}$, against the less massive object which is decaying in nature obeying first order kinetics:

$$
-d F_{R} / d t=k F_{R}
$$

Where: $F_{R}$ is the robotic force [N]

$t$ is time [s]

$k$ is the decaying constant $[1 / s]$

$$
\begin{gathered}
=>-d F_{R} / F_{R}=k d t \\
=>-\int_{F_{R 0}}^{F_{R}} \frac{d F_{R}}{F_{R}}=k \int_{0}^{t} d t \\
\Rightarrow F_{R}=F_{R o} e^{-k t}
\end{gathered}
$$

It can also be reasonably assumed that the massive object in the gravitational relationship has a firing capability to regenerate, reduce or cancel the prevailing robotic force in order to regulate or control the trajectory of the less massive object. The Earth's trajectory is therefore an ellipse in average but a saw-tooth-like when viewed under the microscope (fig. 11). So: the robotics force is a series of decaying force. Although the firing capability of the sun can be imagined, the firing capability of planets is still abstract and mysterious. Not only that, the signaling technique of the solar system is even far beyond comprehension of mankind and science.

For the Newton's law of gravitation to cope with the robotics force, Because of the robotics force's dependency on the angular displacement of the less massive object in the gravitational relationship (fig. 11 and 12), a sinusoidal component must be added to the Newton's Law of Gravitation: 


$$
F_{G}=G \frac{M_{E} M_{S}}{\bar{R}^{2}}\left(1+\varepsilon \times \sin ^{n} \theta\right)
$$

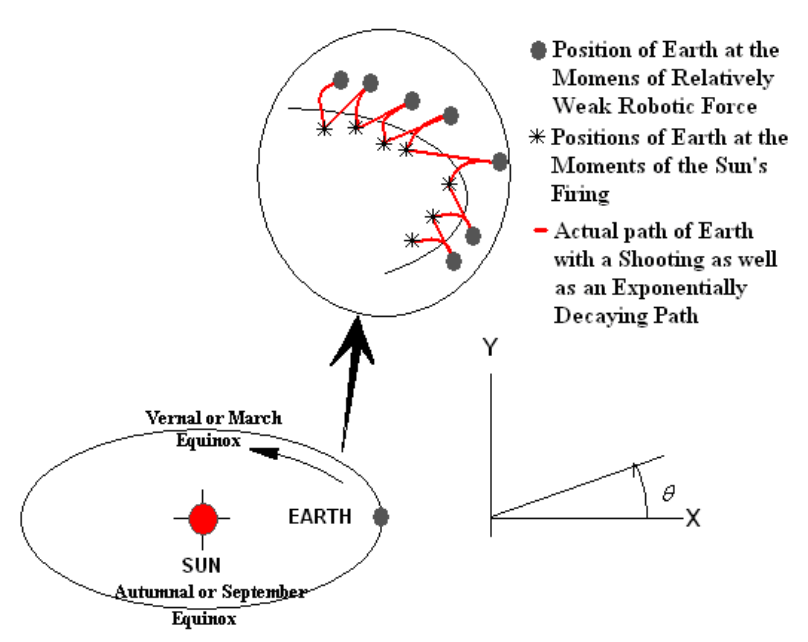

Fig. 11. The Elliptic Trajectory of Earth under Microscope.

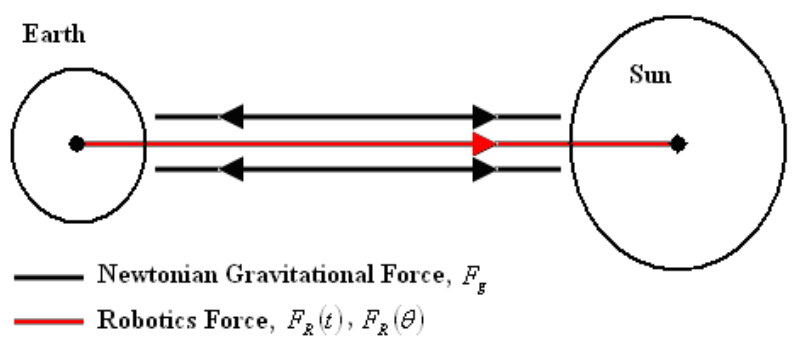

Fig. 12. Extended Newtonian Gravitational Relationship.

Where: $\mathcal{E}$ is the Newcomb's ellipticity constant named after the American astronomer and mathematician Simon Newcomb [-]

$\theta$ is the angular displacement [radians]

$n$ is an even number [-]

$\bar{R}$ is the mean distance between the centers of the two masses $[\mathrm{m}]$

Because of the heliocentric nature of the orbits of the solar system, an exponential term is needed to force heliocentricity:

$$
F_{G}=G \frac{M_{E} M_{S}}{\bar{R}^{2}}\left(1+\varepsilon \times \sin ^{n} \theta+\left(\chi \times e^{\cos \theta}\right)\right)
$$

Where: $\chi$ is the Gauss' heliocentricity constant or Gauss skewing constant named after the German mathematician and physicist Johann Carl Friedrich Gauss [-]

\subsection{Essence of the Quaking of the Sun, Earth and Other Planets}

The crucial part of quakes on the Sun, on Earth and on any other planet is the unilateral robotics force exercised by the massive object to subdue the less-massive object in the gravitational relationship as described in section 7.1 and 7.2. Practically speaking there must exist a sleep time in a gravitational relationship control mechanism, that is, the time in which the less-massive object attempts to go astray as if it were loose after the last successful firing of the massive object (fig. 13) because of the decaying nature of the robotics force. It is the firing which may trigger a quake on the massive object in a gravitational relationship (fig. 13).
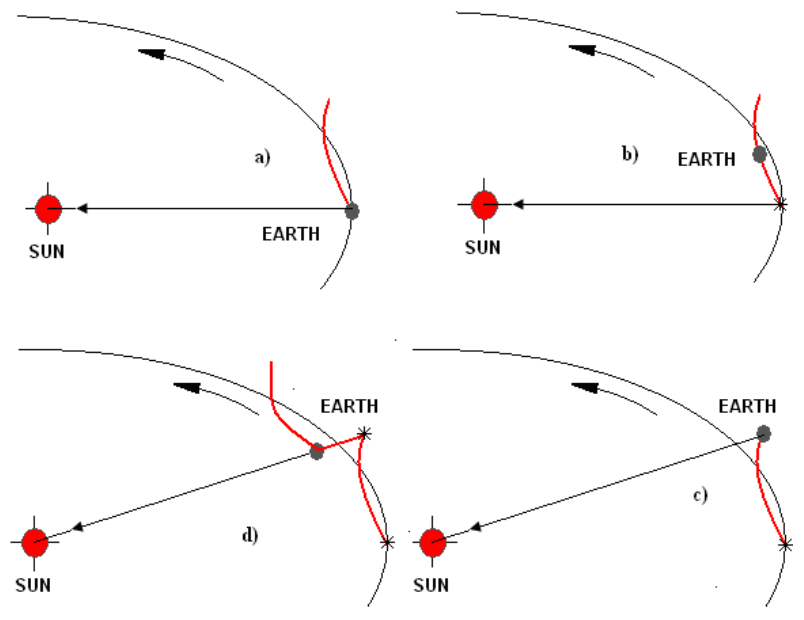

Fig. 13. Sleep Time of the Robotic Force in a Gravitational Relationship: a) After Firing b) During Sleep c) at Firing d) After Firing.

There are four options which best fit the triggering of the quakes on the massive object at the first sight:

- on target long range firing to rotate the robotics force about $180^{\circ}$ (fig. 14a)

- on target short range firing to at angle of about less than $30^{\circ}$ (fig. 14b)

- off target deep short range firing (fig. 14c)

- off target shallow short range firing (fig. 14d)

Which one of the four qualifies? The following discussion tries to shade some light into the jungle:

One: the off target options can be ruled out unless a material fact gets established because the forthcoming robotics force is assumed to phase out the old force and therefore must be directed toward the center of the massive object. The contrary can be proved in that a transition of instability of the system for a while after a quake to a stable system can be recorded. But a conflict of interest still lingers here because a quake is more likely where the two forces meet and above all the off target option is the most instructive of all the options and it seems to be offering a plausible clue on how to predict an immediate big quake.

Two: the on target long range can be ruled out for the simple reason that there are fewer quakes of magnitude 8.0 and above on Earth in the period between the years 1900 to 2015 (table A6), whereas there are about 24 opportunities of that sort predominantly on the 1 st and the 3 rd quarter of the moon.

Three: the second on target option has a chance to be the trigger because its force is towards the center of the massive object - hence its name on target - at the first place. At the second place, the likelihood of a quake at deep sees is low (fig. A3, table A6) which means that water will simply 
dampen any quakes.

Four: a close look at the major quakes between the years 1900 and 2015 reveals that most of these quakes happen offshore which suggests that a strike in air and a strike in water has got no effect in terms of producing an Earth Quake (fig. 15), whereas a strike subsurface above sea level as well as a strike under the sea bed will most likely generate quake waves to be recorded on the Richter quake wave recorder.

Five: the major quakes in the years between 1900 and 2015 happed predominantly at around the 1 st and last quarter of the moon (table A7) whereas the likelihood of a major quake close to a penumbral eclipse is low (table A8).
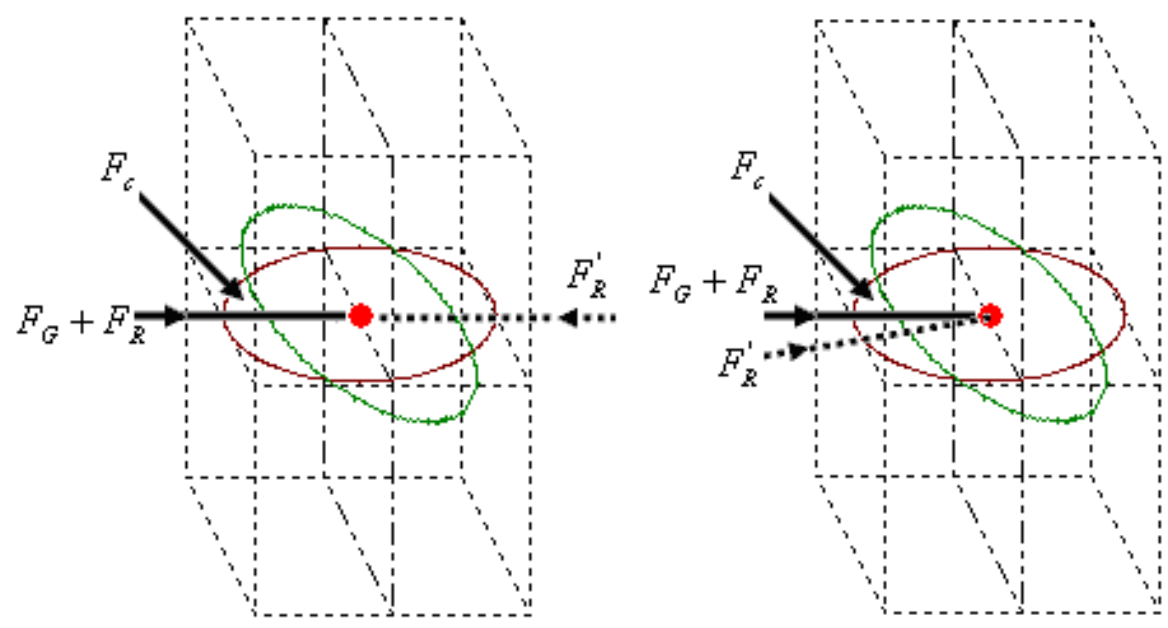

Fig. 14. a) On Target $180^{\circ}$ Rotation of the Robotics Force b) On Target Short Range Firing.
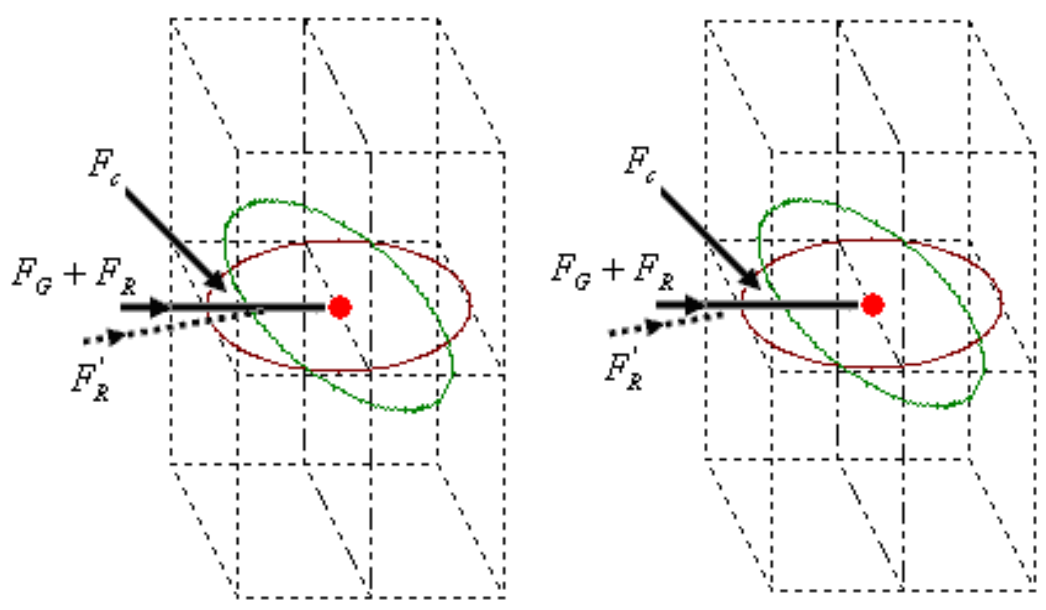

Fig. 14. c) Off Target Deep Short Range Firing d) Off Target Shallow Short Range Firing.

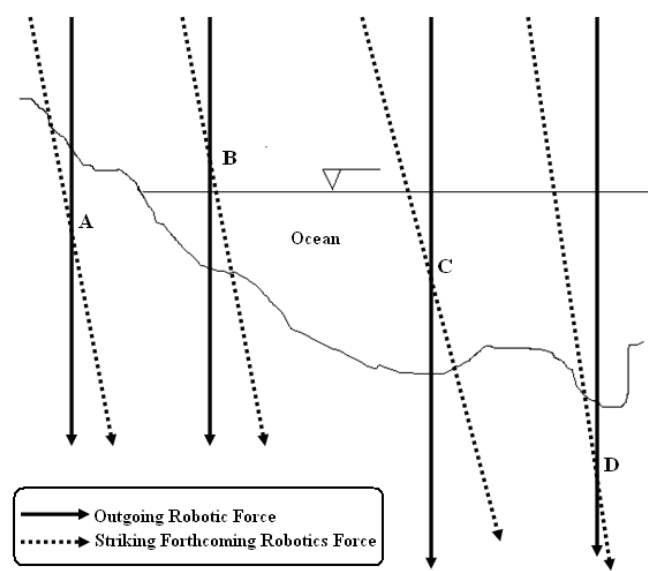

Fig. 15. Quake Strike Scenario: A-Above See Level Strike, B-Air Strike, C - Water Strike, D - Undersea Bed Strike.

\subsection{Laws of the Universe}

Because the orbits of all moving celestial bodies in the Solar system prove to be elliptic and because the gravitational force acting upon the moon in its relation to Earth is relatively higher at the $1^{\text {st }}$ and $3^{\text {rd }}$ quarter of the moon than that at the new moon and the full moon save the influences of the Earth's Equinoxes and the influence of the moon's changing of its orbit's plane relative to the syzygy configuration, it follows that:

1) every planet in the Solar system must have at least one natural satellite.

2) the gravitation force upon planets and natural satellites will depend upon their angular displacements in their gravitational relationship in terms of equation (8)

3 ) the immediate environment of the Sun cannot be subdued by its planets in terms of gravitational 
relationship save the sudden surge of the gravitational pull or ergonomic assaulting of the Sun. The same holds for the case of planets in relation to their natural satellites.

4) the orbits of all planets and natural satellites dynamically shift up and down through a central syzygy configuration to occasion eclipses of the Sun, eclipses of the planets as well as eclipses of the satellites.

That is to say:

$$
\sum_{k=0}^{k=n} \sum_{j=0}^{j=m}\left({ }_{p} F_{G}\right)_{k} \times\left({ }_{s} F_{G}\right)_{j}=\text { const }=\lambda_{U}
$$

Where: ${ }_{p} F_{G}$ is the magnitude of gravitational force of an individual planet in the Sun-planet gravitational relationship in terms of equation (8)

${ }_{s} F_{G}$ is the magnitude of gravitational force of an individual satellite in the planet-satellite gravitational relationship in terms of equation (8)

$$
\lambda_{U} \text { is a constant of the universe }\left[N^{2}\right]
$$

The model assumes that natural satellites do not have moons.

\subsection{Solar System Robotics and Automation}

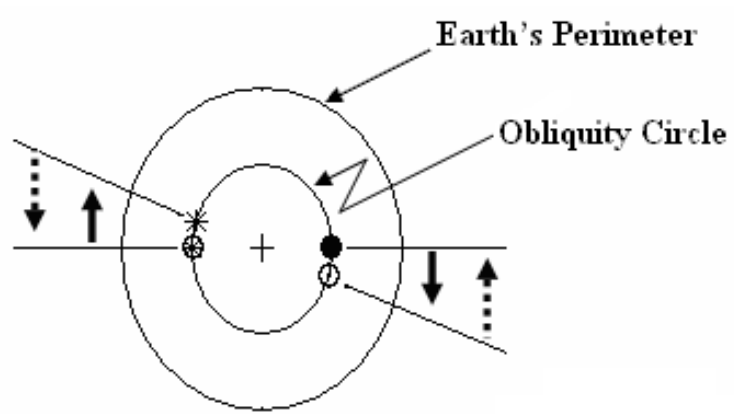

- North Pole at the Solstices

$\odot$ North Pole at the Equinoxes

\section{South Pole at the Solstices}

\section{* South Pole at the Equinoxes}

Fig. 16. Top View of Earth with the North Pole on Top.

If the solar system can be thought to be designed, then all planets and all natural satellites must have unique points to be remote sensed for location or identification by the massive object in their gravitational relationship at any time $t$. Because all planets and most likely all natural satellites rotate about an axis to make a day and night, the axis of rotation must be inclined at an angle to make the poles uniquely reachable at any time t. And, a perfect automation would only be reached only if only one of the two poles would be uniquely reached at a time. With the exception of the moment at the Equinoxes, all that seems to be happening fine with the model planet Earth. To overcome this design problem, Earth and in deed the other planets must rotate a bit about the Main Axis such that only one pole is uniquely exposed to the Sun at a the Equinoxes. It is as if the poles are responding to get the Sun light early shortly before the Equinoxes and will start turning back shortly after the Equinoxes (fig. 16).

Assuming that the North and South Pole of Earth have got different properties in terms of gravitational reflectivity, temperature and light reflectivity (albedo), which seems to be true, then a difference between the distances from the Sun to the perihelion and aphelion must be there if a response of the control force to regulate planet's trajectory is simply relying on receipt of an echoing signal from the planet's poles having two different reflectivity.

The author of this publication believes that the blue print of the instruction of the automation of the solar system, like any other similar system elsewhere in the cosmos, is similar to the code stored in the DNA of biological systems. The author is curious about the functions of the black holes in the cosmos.

\subsection{Climate Distribution}

Without the moon, life on Earth would be unimaginable. The whole game of Earth and the moon to rotate in elliptical orbits enables the mixing of water in the big water bodies and enables the mixing of air in the Earth's atmosphere. The phenomenon of low and hide manifests the agitator function of Earth's build in commanding heights.

\section{Conclusion}

One: in order that the position of Earth in its trajectory around the Sun can be uniquely identified by the solar system:

- Earth must be rotate around the obliquity axis.

- Earth must rotate about the Main axis in a to-and-from fashion with a period of about 365.24 days to be uniquely identified through a single pole

Two: the properties of the Earth's North Pole must differ from those at the Earth's South Pole in terms of gravitational reflectivity to uniquely differentiate them in a gravitational relationship

Three: The difference in gravitational reflectivity of the poles will determine the difference in the distance between the Sun to the Earth's perihelion and Earth's aphelion.

Four: The gravitational force in a gravitational relationship will depend on the angular displacement of the less massive object and that the trajectory of the less massive object will be elliptic:

$$
F_{G}=G \frac{M_{E} M_{S}}{\bar{R}^{2}}\left(1+\varepsilon \times \sin ^{n} \theta+\left(\chi \times e^{\cos \theta}\right)\right)
$$

The massive object will fire a decaying robotics force to set or rectify the position of the less massive object.

Five: Every planet in the Solar system must have at least one natural satellite.

Six: The immediate environment of the massive object in a gravitational relationship cannot be subdued by the less massive object. The low and high tides are a result of the 
Earth side decaying unilateral robotics force mounted to subdue the moon. A surge of tidal waves will predominantly happen at the first and last quarter of the moon as well as exceptionally at the new and full moon at around the Earth's Equinoxes.

Seven: The forces of gravity acting upon all the planets and their natural satellites must obey the universal law of the universe:

\section{Appendix A}

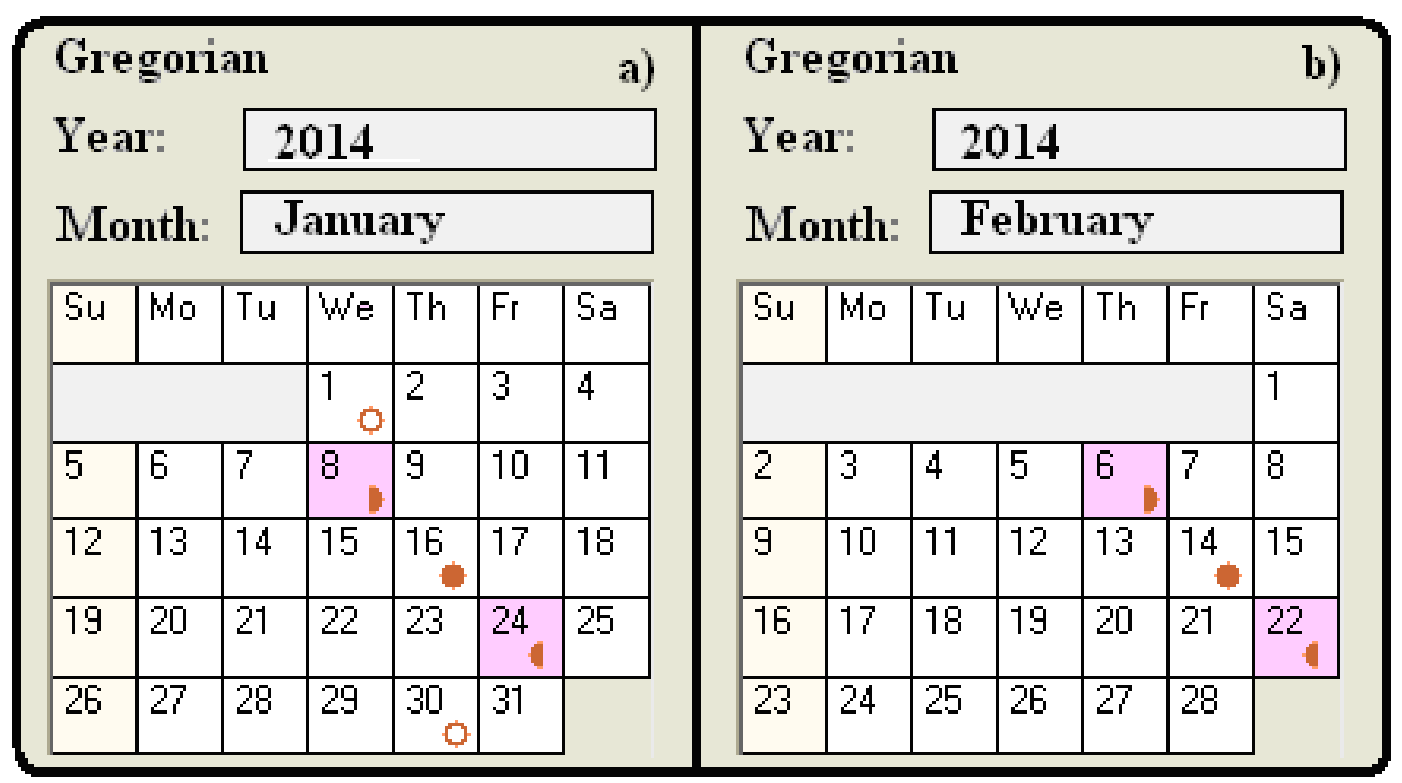

Fig. A1. New Moon, First Quarter Moon, Full Moon, and Last Quarter

Moon Dates in the months January and February 2014; Moon

Phases Algorithm Source: [3]

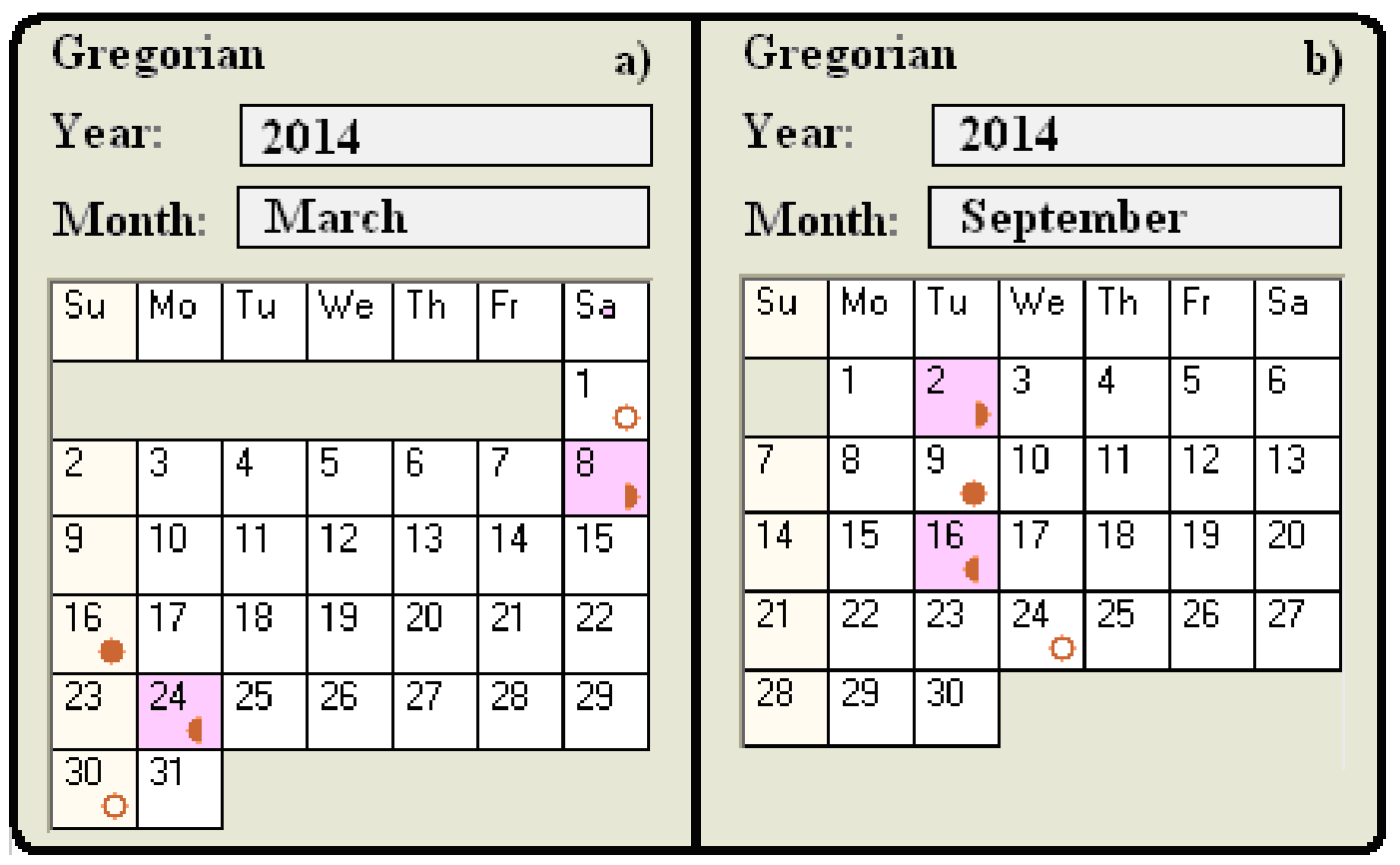

Fig. A2. New Moon, First Quarter Moon, Full Moon, and Last Quarter.

Moon Dates in the months March and September 2014; Moon

Phases Algorithm Source: [3] 


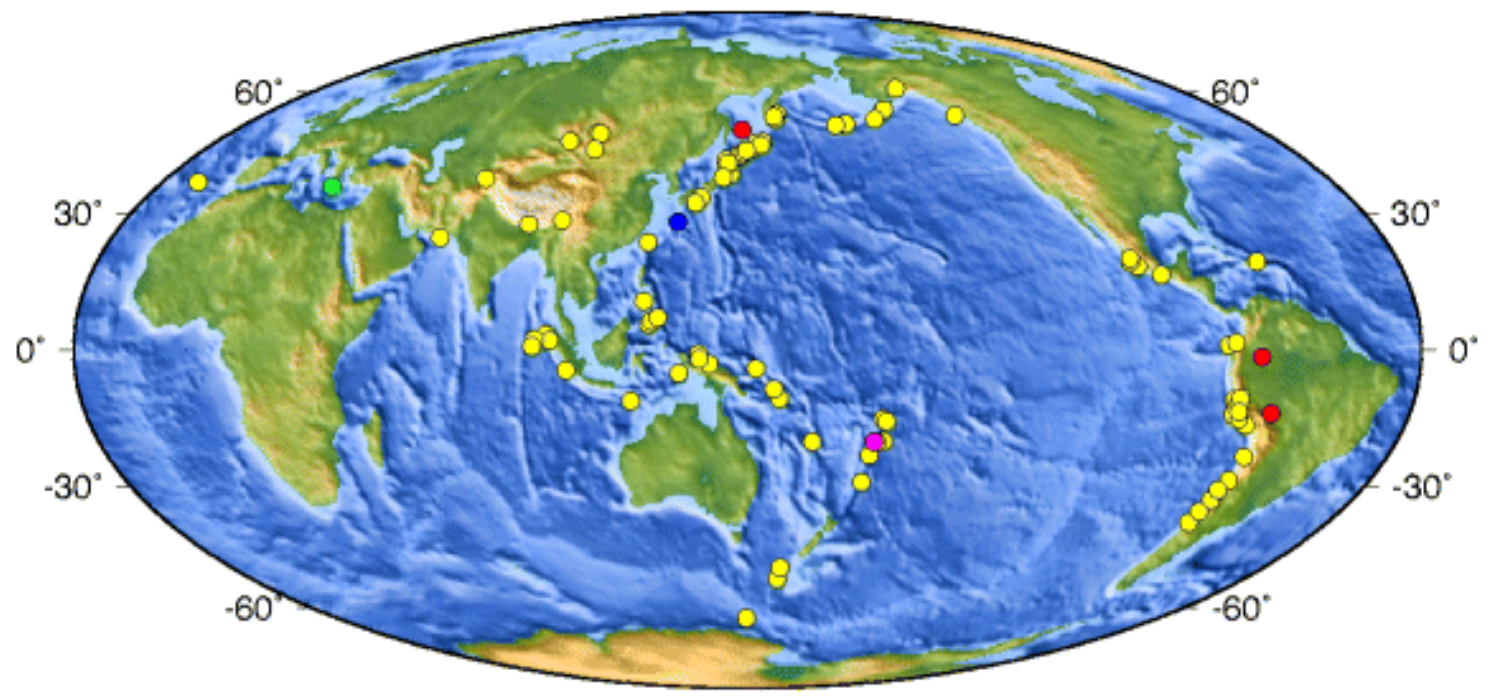

Magnitude 8.0 and Greater Earthquakes Since 1900

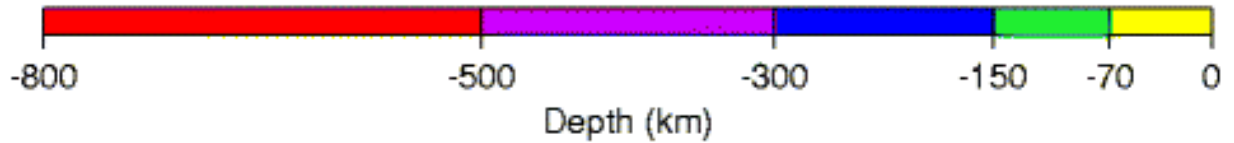

Fig. A3. Map of 8.0 and Greater Earth Quake Epicenters for the Years 1900 - 2015 [5].

Table A1. Tide Arrival Times at Tonga Tongatapu for Jan, Feb, Mar and Sep 2014 [4].

\begin{tabular}{|c|c|c|}
\hline Date & Low Tide UTC Time & High Tide UTC Time \\
\hline $01 / 01 / 2014$ & $12: 00$ & 06:00 \\
\hline $01 / 02 / 2014$ & 13:00 & 07:00 \\
\hline $01 / 03 / 2014$ & $14: 00$ & 08:00 \\
\hline $01 / 04 / 2014$ & $15: 00$ & 09:00 \\
\hline $01 / 05 / 2014$ & $16: 00$ & 10:00 \\
\hline $01 / 06 / 2014$ & $17: 00$ & $\underline{11: 00}$ \\
\hline $01 / 07 / 2014$ & $\underline{18: 00}$ & $\underline{00: 00}$ \\
\hline 01/08/2014 & $\underline{07: 00}$ & 00:00 \\
\hline 01/09/2014 & $\overline{08: 00}$ & 01:00 \\
\hline $01 / 10 / 2014$ & 09:00 & 02:00 \\
\hline 01/11/2014 & 09:00 & 03:00 \\
\hline $01 / 12 / 2014$ & 10:00 & 04:00 \\
\hline 01/13/2014 & 11:00 & 05:00 \\
\hline $01 / 14 / 2014$ & $12: 00$ & 06:00 \\
\hline $01 / 15 / 2014$ & 13:00 & 06:00 \\
\hline $01 / 16 / 2014$ & 13:00 & 07:00 \\
\hline $01 / 17 / 2014$ & $14: 00$ & 07:00 \\
\hline $01 / 18 / 2014$ & $14: 00$ & 08:00 \\
\hline 01/19/2014 & 15:00 & $\underline{09: 00}$ \\
\hline $01 / 20 / 2014$ & $16: 00$ & $\underline{22: 00}$ \\
\hline $01 / 21 / 2014$ & $16: 00$ & 23:00 \\
\hline $01 / 22 / 2014$ & $\underline{17: 00}$ & 23:00 \\
\hline $01 / 23 / 2014$ & $\underline{06: 00}$ & 23:00 \\
\hline $01 / 24 / 2014$ & $\underline{19: 00}$ & 00:00 \\
\hline $01 / 25 / 2014$ & $\underline{20: 00}$ & 01:00 \\
\hline $01 / 26 / 2014$ & $\underline{08: 00}$ & 02:00 \\
\hline $01 / 27 / 2014$ & 09:00 & 03:00 \\
\hline $01 / 28 / 2014$ & 10:00 & 04:00 \\
\hline
\end{tabular}

\begin{tabular}{lll}
\hline Date & Low Tide UTC Time & High Tide UTC Time \\
\hline 01/29/2014 & $11: 00$ & $05: 00$ \\
01/30/2014 & $12: 00$ & $06: 00$ \\
01/31/2014 & $13: 00$ & $07: 00$ \\
02/01/2014 & $14: 00$ & $08: 00$ \\
02/02/2014 & $15: 00$ & $\underline{09: 00}$ \\
02/03/2014 & $16: 00$ & $\underline{22: 00}$ \\
02/04/2014 & $\underline{17: 00}$ & $23: 00$ \\
02/05/2014 & $\underline{05: 00}$ & $23: 00$ \\
02/06/2014 & $06: 00$ & $00: 00$ \\
02/07/2014 & $07: 00$ & $01: 00$ \\
02/08/2014 & $08: 00$ & $02: 00$ \\
02/09/2014 & $09: 00$ & $03: 00$ \\
02/10/2014 & $10: 00$ & $03: 00$ \\
02/11/2014 & $11: 00$ & $04: 00$ \\
02/12/2014 & $12: 00$ & $05: 00$ \\
02/13/2014 & $12: 00$ & $06: 00$ \\
02/14/2014 & $13: 00$ & $06: 00$ \\
02/15/2014 & $13: 00$ & $07: 00$ \\
02/16/2014 & $14: 00$ & $08: 00$ \\
02/17/2014 & $15: 00$ & $08: 00$ \\
02/18/2014 & $15: 00$ & $\underline{09: 00}$ \\
02/19/2014 & $16: 00$ & $\underline{22: 00}$ \\
02/20/2014 & $\underline{17: 00}$ & $23: 00$ \\
02/21/2014 & $\underline{05: 00}$ & $23: 00$ \\
02/22/2014 & $06: 00$ & $00: 00$ \\
02/23/2014 & $07: 00$ & $01: 00$ \\
02/24/2014 & $08: 00$ & $01: 00$ \\
02/25/2014 & $09: 00$ & $02: 00$ \\
02/26/2014 & $10: 00$ & $03: 00$ \\
$02 / 27 / 2014$ & $11: 00$ & $04: 00$ \\
\hline
\end{tabular}




\begin{tabular}{|c|c|c|}
\hline Date & Low Tide UTC Time & High Tide UTC Time \\
\hline $02 / 28 / 2014$ & $12: 00$ & 05:00 \\
\hline 03/01/2014 & $13: 00$ & $\underline{06: 00}$ \\
\hline 03/02/2014 & $14: 00$ & $20: 00$ \\
\hline 03/03/2014 & $\underline{15: 00}$ & 08:00 \\
\hline $03 / 04 / 2014$ & $\underline{03: 00}$ & 09:00 \\
\hline 03/05/2014 & 04:00 & $22: 00$ \\
\hline $03 / 06 / 2014$ & 05:00 & 23:00 \\
\hline 03/07/2014 & 06:00 & 00:00 \\
\hline 03/08/2014 & 07:00 & 00:00 \\
\hline 03/09/2014 & 08:00 & 01:00 \\
\hline 03/10/2014 & 08:00 & 02:00 \\
\hline $03 / 11 / 2014$ & 09:00 & 03:00 \\
\hline $03 / 12 / 2014$ & 10:00 & 04:00 \\
\hline 03/13/2014 & 11:00 & 04:00 \\
\hline 03/14/2014 & 12:00 & 05:00 \\
\hline $03 / 15 / 2014$ & $12: 00$ & $\underline{06: 00}$ \\
\hline $03 / 16 / 2014$ & 13:00 & 19:00 \\
\hline 03/17/2014 & 13:00 & $\overline{20: 00}$ \\
\hline $03 / 18 / 2014$ & $\underline{14: 00}$ & 20:00 \\
\hline 03/19/2014 & $\underline{02: 00}$ & 21:00 \\
\hline $03 / 20 / 2014$ & 03:00 & 22:00 \\
\hline $03 / 21 / 2014$ & 04:00 & 22:00 \\
\hline $03 / 22 / 2014$ & 05:00 & 23:00 \\
\hline 03/23/2014 & 06:00 & 00:00 \\
\hline 03/24/2014 & 07:00 & 00:00 \\
\hline $03 / 25 / 2014$ & 08:00 & 01:00 \\
\hline 03/26/2014 & 09:00 & 02:00 \\
\hline 03/27/2014 & 10:00 & 03:00 \\
\hline $03 / 28 / 2014$ & 11:00 & $\underline{17: 00}$ \\
\hline 03/29/2014 & $12: 00$ & $\overline{18: 00}$ \\
\hline 03/30/2014 & $\underline{12: 00}$ & 19:00 \\
\hline $03 / 31 / 2014$ & $\underline{01: 00}$ & 20:00 \\
\hline$\cdots$ & $\cdots$ & ... \\
\hline $09 / 1 / 2014$ & 18:00 & 11:00 \\
\hline $09 / 2 / 2014$ & 19:00 & $12: 00$ \\
\hline 09/3/2014 & 20:00 & 13:00 \\
\hline $09 / 4 / 2014$ & 21:00 & 14:00 \\
\hline 09/5/2014 & 21:00 & $15: 00$ \\
\hline 09/6/2014 & 23:00 & 16:00 \\
\hline 09/7/2014 & 23:00 & $17: 00$ \\
\hline 09/8/2014 & 00:00 & 18:00 \\
\hline 09/9/2014 & 00:00 & 19:00 \\
\hline 09/10/2014 & 01:00 & 20:00 \\
\hline 09/11/2014 & $\underline{02: 00}$ & $\underline{08: 00}$ \\
\hline $09 / 12 / 2014$ & $\overline{15: 00}$ & $\overline{09: 00}$ \\
\hline 09/13/2014 & $\overline{16: 00}$ & 10:00 \\
\hline 09/14/2014 & $17: 00$ & 11:00 \\
\hline 09/15/2014 & 18:00 & $12: 00$ \\
\hline $09 / 16 / 2014$ & 19:00 & $13: 00$ \\
\hline 09/17/2014 & 20:00 & $14: 00$ \\
\hline 09/18/2014 & 21:00 & $15: 00$ \\
\hline 09/19/2014 & $22: 00$ & $16: 00$ \\
\hline 09/20/2014 & 23:00 & $16: 00$ \\
\hline $09 / 21 / 2014$ & $23: 00$ & $17: 00$ \\
\hline $09 / 22 / 2014$ & 00:00 & 18:00 \\
\hline $09 / 23 / 2014$ & 00:00 & 06:00 \\
\hline $09 / 24 / 2014$ & $\overline{13: 00}$ & $\overline{07: 00}$ \\
\hline $09 / 25 / 2014$ & $\overline{01: 00}$ & 07:00 \\
\hline $09 / 26 / 2014$ & 14:00 & 08:00 \\
\hline
\end{tabular}

\begin{tabular}{lll}
\hline Date & Low Tide UTC Time & High Tide UTC Time \\
\hline 09/27/2014 & $15: 00$ & $08: 00$ \\
09/28/2014 & $16: 00$ & $09: 00$ \\
$09 / 29 / 2014$ & $16: 00$ & $10: 00$ \\
$09 / 30 / 2014$ & $17: 00$ & $11: 00$ \\
\hline
\end{tabular}

Table A2. Tide Arrival Times at Tonga Tongatapu for Apr-Jul 2015 [4].

\begin{tabular}{|c|c|c|}
\hline Date & Low Tide UTC Time & High Tide UTC Time \\
\hline $01 / 01 / 2015$ & $10: 00$ & 04:00 \\
\hline $01 / 02 / 2015$ & 11:00 & 04:00 \\
\hline $01 / 03 / 2015$ & $12: 00$ & 05:00 \\
\hline $01 / 04 / 2015$ & $13: 00$ & 06:00 \\
\hline $01 / 05 / 2015$ & 13:00 & 07:00 \\
\hline $01 / 06 / 2015$ & $14: 00$ & 08:00 \\
\hline 01/07/2015 & $15: 00$ & 08:00 \\
\hline 01/08/2015 & $15: 00$ & 09:00 \\
\hline 01/09/2015 & $16: 00$ & 10:00 \\
\hline $01 / 10 / 2015$ & $16: 00$ & $\underline{23: 00}$ \\
\hline $01 / 11 / 2015$ & $17: 00$ & $\overline{23: 00}$ \\
\hline $01 / 12 / 2015$ & 18:00 & 00:00 \\
\hline $01 / 13 / 2015$ & $\underline{19: 00}$ & 00:00 \\
\hline $01 / 14 / 2015$ & $\overline{07: 00}$ & 01:00 \\
\hline $01 / 15 / 2015$ & 08:00 & 02:00 \\
\hline $01 / 16 / 2015$ & 09:00 & 03:00 \\
\hline $01 / 17 / 2015$ & 10:00 & 03:00 \\
\hline $01 / 18 / 2015$ & 11:00 & 04:00 \\
\hline 01/19/2015 & $12: 00$ & 05:00 \\
\hline $01 / 20 / 2015$ & 13:00 & 06:00 \\
\hline $01 / 21 / 2015$ & 13:00 & 07:00 \\
\hline $01 / 22 / 2015$ & $14: 00$ & 08:00 \\
\hline $01 / 23 / 2015$ & $15: 00$ & 09:00 \\
\hline $01 / 24 / 2015$ & $16: 00$ & $10: 00$ \\
\hline $01 / 25 / 2015$ & $17: 00$ & $\underline{23: 00}$ \\
\hline $01 / 26 / 2015$ & $\underline{18: 00}$ & 00:00 \\
\hline $01 / 27 / 2015$ & $\underline{07: 00}$ & 00:00 \\
\hline $01 / 28 / 2015$ & $\overline{08: 00}$ & 01:00 \\
\hline $01 / 29 / 2015$ & 09:00 & 02:00 \\
\hline $01 / 30 / 2015$ & 10:00 & 03:00 \\
\hline $01 / 31 / 2015$ & 11:00 & 04:00 \\
\hline $02 / 01 / 2015$ & 11:00 & 05:00 \\
\hline $02 / 02 / 2015$ & $12: 00$ & 06:00 \\
\hline $02 / 03 / 2015$ & 13:00 & 07:00 \\
\hline $02 / 04 / 2015$ & $14: 00$ & 07:00 \\
\hline $02 / 05 / 2015$ & $14: 00$ & 08:00 \\
\hline $02 / 06 / 2015$ & 15:00 & 08:00 \\
\hline $02 / 07 / 2015$ & 15:00 & $\underline{21: 00}$ \\
\hline $02 / 08 / 2015$ & 16:00 & $\underline{10: 00}$ \\
\hline $02 / 09 / 2015$ & 17:00 & $\underline{23: 00}$ \\
\hline $02 / 10 / 2015$ & $\underline{17: 00}$ & $23: 00$ \\
\hline $02 / 11 / 2015$ & $\underline{06: 00}$ & 00:00 \\
\hline $02 / 12 / 2015$ & $\overline{07: 00}$ & 00:00 \\
\hline $02 / 13 / 2015$ & 08:00 & 01:00 \\
\hline $02 / 14 / 2015$ & 09:00 & 02:00 \\
\hline $02 / 15 / 2015$ & 10:00 & 03:00 \\
\hline $02 / 16 / 2015$ & 11:00 & 04:00 \\
\hline $02 / 17 / 2015$ & 11:00 & 05:00 \\
\hline $02 / 18 / 2015$ & $12: 00$ & 06:00 \\
\hline 02/19/2015 & 13:00 & 07:00 \\
\hline $02 / 20 / 2015$ & $14: 00$ & 08:00 \\
\hline
\end{tabular}




\begin{tabular}{|c|c|c|c|c|c|}
\hline Date & Low Tide UTC Time & High Tide UTC Time & Date & Low Tide UTC Time & High Tide UTC Time \\
\hline $02 / 21 / 2015$ & $15: 00$ & $\underline{09: 00}$ & $04 / 21 / 2015$ & 03:00 & 21:00 \\
\hline $02 / 22 / 2015$ & $\underline{16: 00}$ & $\underline{22: 00}$ & $04 / 22 / 2015$ & 03:00 & $22: 00$ \\
\hline $02 / 23 / 2015$ & $\underline{04: 00}$ & 23:00 & $04 / 23 / 2015$ & 04:00 & 23:00 \\
\hline $02 / 24 / 2015$ & 05:00 & 00:00 & $04 / 24 / 2015$ & 05:00 & 00:00 \\
\hline $02 / 25 / 2015$ & 06:00 & 00:00 & $04 / 25 / 2015$ & 06:00 & 00:00 \\
\hline $02 / 26 / 2015$ & 07:00 & 01:00 & $04 / 26 / 2015$ & 07:00 & 01:00 \\
\hline $02 / 27 / 2015$ & 08:00 & 02:00 & $04 / 27 / 2015$ & 08:00 & 02:00 \\
\hline $02 / 28 / 2015$ & 09:00 & 03:00 & $04 / 28 / 2015$ & 09:00 & $15: 00$ \\
\hline $03 / 01 / 2015$ & $10: 00$ & 04:00 & $04 / 29 / 2015$ & $10: 00$ & 16:00 \\
\hline 03/02/2015 & 11:00 & 05:00 & $04 / 30 / 2015$ & 10:00 & $\underline{04: 00}$ \\
\hline 03/03/2015 & $12: 00$ & 05:00 & $05 / 01 / 2015$ & $\underline{11: 00}$ & $\underline{17: 00}$ \\
\hline $03 / 04 / 2015$ & $12: 00$ & 06:00 & $05 / 02 / 2015$ & $\underline{00: 00}$ & 18:00 \\
\hline 03/05/2015 & $13: 00$ & 07:00 & $05 / 03 / 2015$ & 00:00 & 19:00 \\
\hline 03/06/2015 & $14: 00$ & 07:00 & $05 / 04 / 2015$ & 01:00 & 19:00 \\
\hline $03 / 07 / 2015$ & $14: 00$ & 08:00 & $05 / 05 / 2015$ & 02:00 & $20: 00$ \\
\hline $03 / 08 / 2015$ & 15:00 & $\underline{21: 00}$ & $05 / 06 / 2015$ & 02:00 & 21:00 \\
\hline $03 / 09 / 2015$ & $\underline{15: 00}$ & $\underline{09: 00}$ & $05 / 07 / 2015$ & 03:00 & 21:00 \\
\hline $03 / 10 / 2015$ & 04:00 & $\underline{22: 00}$ & $05 / 08 / 2015$ & 04:00 & $22: 00$ \\
\hline 03/11/2015 & 04:00 & 23:00 & $05 / 09 / 2015$ & 04:00 & $\underline{23: 00}$ \\
\hline $03 / 12 / 2015$ & 05:00 & 23:00 & $05 / 10 / 2015$ & 05:00 & $\underline{12: 00}$ \\
\hline $03 / 13 / 2015$ & 06:00 & 00:00 & $05 / 11 / 2015$ & $06: 00$ & 00:00 \\
\hline $03 / 14 / 2015$ & 07:00 & 01:00 & $05 / 12 / 2015$ & 07:00 & $\underline{14: 00}$ \\
\hline $03 / 15 / 2015$ & 08:00 & 02:00 & $05 / 13 / 2015$ & $\underline{08: 00}$ & $15: 00$ \\
\hline $03 / 16 / 2015$ & 09:00 & 02:00 & $05 / 14 / 2015$ & $22: 00$ & $16: 00$ \\
\hline $03 / 17 / 2015$ & 10:00 & $\underline{03: 00}$ & $05 / 15 / 2015$ & 23:00 & $16: 00$ \\
\hline $03 / 18 / 2015$ & 11:00 & $\underline{17: 00}$ & $05 / 16 / 2015$ & 23:00 & $17: 00$ \\
\hline 03/19/2015 & $12: 00$ & 18:00 & $05 / 17 / 2015$ & 00:00 & $18: 00$ \\
\hline $03 / 20 / 2015$ & 13:00 & 19:00 & $05 / 18 / 2015$ & 01:00 & 19:00 \\
\hline $03 / 21 / 2015$ & $\underline{01: 00}$ & $20: 00$ & $05 / 19 / 2015$ & 01:00 & 20:00 \\
\hline $03 / 22 / 2015$ & 02:00 & $21: 00$ & $05 / 20 / 2015$ & 02:00 & $21: 00$ \\
\hline $03 / 23 / 2015$ & 03:00 & 09:00 & $05 / 21 / 2015$ & 03:00 & 22:00 \\
\hline $03 / 24 / 2015$ & 04:00 & $22: 00$ & $05 / 22 / 2015$ & 04:00 & $22: 00$ \\
\hline $03 / 25 / 2015$ & 05:00 & 23:00 & $05 / 23 / 2015$ & 05:00 & $23: 00$ \\
\hline $03 / 26 / 2015$ & 06:00 & 00:00 & $05 / 24 / 2015$ & 06:00 & 00:00 \\
\hline $03 / 27 / 2015$ & 07:00 & 00:00 & $05 / 25 / 2015$ & 06:00 & $\underline{00: 00}$ \\
\hline $03 / 28 / 2015$ & 08:00 & 01:00 & $05 / 26 / 2015$ & 07:00 & 14:00 \\
\hline $03 / 29 / 2015$ & 09:00 & 02:00 & $05 / 27 / 2015$ & 08:00 & $14: 00$ \\
\hline 03/30/2015 & $10: 00$ & 03:00 & $05 / 28 / 2015$ & $\underline{09: 00}$ & $15: 00$ \\
\hline $03 / 31 / 2015$ & 10:00 & 04:00 & $05 / 29 / 2015$ & $22: 00$ & $16: 00$ \\
\hline $04 / 01 / 2015$ & $11: 00$ & $\underline{05: 00}$ & $05 / 30 / 2015$ & 23:00 & $17: 00$ \\
\hline $04 / 02 / 2015$ & $12: 00$ & $\underline{18: 00}$ & $05 / 31 / 2015$ & 23:00 & $17: 00$ \\
\hline $04 / 03 / 2015$ & $12: 00$ & 18:00 & $06 / 01 / 2015$ & 00:00 & $18: 00$ \\
\hline 04/04/2015 & $\underline{13: 00}$ & 19:00 & $06 / 02 / 2015$ & 00:00 & 19:00 \\
\hline $04 / 05 / 2015$ & $\underline{01: 00}$ & 20:00 & $06 / 03 / 2015$ & 01:00 & 19:00 \\
\hline $04 / 06 / 2015$ & 02:00 & $20: 00$ & $06 / 04 / 2015$ & 02:00 & $20: 00$ \\
\hline 04/07/2015 & 03:00 & 21:00 & $06 / 05 / 2015$ & 03:00 & 21:00 \\
\hline $04 / 08 / 2015$ & 03:00 & $22: 00$ & $06 / 06 / 2015$ & 03:00 & $22: 00$ \\
\hline $04 / 09 / 2015$ & 04:00 & $22: 00$ & $06 / 07 / 2015$ & 04:00 & 23:00 \\
\hline $04 / 10 / 2015$ & 05:00 & 23:00 & $06 / 08 / 2015$ & 05:00 & $\underline{12: 00}$ \\
\hline $04 / 11 / 2015$ & 06:00 & 00:00 & $06 / 09 / 2015$ & 06:00 & $\underline{00: 00}$ \\
\hline $04 / 12 / 2015$ & 07:00 & 00:00 & $06 / 10 / 2015$ & 07:00 & 13:00 \\
\hline $04 / 13 / 2015$ & 08:00 & $\underline{01: 00}$ & $06 / 11 / 2015$ & 21:00 & $14: 00$ \\
\hline $04 / 14 / 2015$ & $\underline{09: 00}$ & $\underline{15: 00}$ & $06 / 12 / 2015$ & 22:00 & $15: 00$ \\
\hline $04 / 15 / 2015$ & $22: 00$ & 03:00 & $06 / 13 / 2015$ & $23: 00$ & 16:00 \\
\hline $04 / 16 / 2015$ & $\underline{23: 00}$ & $\underline{17: 00}$ & $06 / 14 / 2015$ & 23:00 & $17: 00$ \\
\hline $04 / 17 / 2015$ & $11: 00$ & 18:00 & $06 / 15 / 2015$ & 00:00 & $18: 00$ \\
\hline $04 / 18 / 2015$ & $\overline{00: 00}$ & 19:00 & $06 / 16 / 2015$ & 00:00 & 19:00 \\
\hline $04 / 19 / 2015$ & 01:00 & 19:00 & $06 / 17 / 2015$ & 01:00 & 20:00 \\
\hline $04 / 20 / 2015$ & 02:00 & $20: 00$ & $06 / 18 / 2015$ & 02:00 & $20: 00$ \\
\hline
\end{tabular}




\begin{tabular}{|c|c|c|}
\hline Date & Low Tide UTC Time & High Tide UTC Time \\
\hline $06 / 19 / 2015$ & 03:00 & 21:00 \\
\hline $06 / 20 / 2015$ & 04:00 & $22: 00$ \\
\hline $06 / 21 / 2015$ & 04:00 & 23:00 \\
\hline $06 / 22 / 2015$ & 05:00 & 11:00 \\
\hline $06 / 23 / 2015$ & 06:00 & $12: 00$ \\
\hline $06 / 24 / 2015$ & 06:00 & $13: 00$ \\
\hline $06 / 25 / 2015$ & $\underline{07: 00}$ & $14: 00$ \\
\hline $06 / 26 / 2015$ & $\underline{21: 00}$ & $14: 00$ \\
\hline $06 / 27 / 2015$ & $\overline{22: 00}$ & $15: 00$ \\
\hline $06 / 28 / 2015$ & $22: 00$ & $16: 00$ \\
\hline 06/29/2015 & 23:00 & $17: 00$ \\
\hline $06 / 30 / 2015$ & 23:00 & $17: 00$ \\
\hline 07/01/2015 & 00:00 & 18:00 \\
\hline 07/02/2015 & 01:00 & 19:00 \\
\hline 07/03/2015 & 01:00 & 20:00 \\
\hline 07/04/2015 & 02:00 & 21:00 \\
\hline $07 / 05 / 2015$ & 03:00 & $\underline{22: 00}$ \\
\hline 07/06/2015 & 04:00 & $\overline{10: 00}$ \\
\hline 07/07/2015 & 05:00 & $11: 00$ \\
\hline $07 / 08 / 2015$ & $\underline{06: 00}$ & $12: 00$ \\
\hline $07 / 09 / 2015$ & $\underline{19: 00}$ & 13:00 \\
\hline $07 / 10 / 2015$ & $20: 00$ & $14: 00$ \\
\hline $07 / 11 / 2015$ & 21:00 & $15: 00$ \\
\hline
\end{tabular}

\begin{tabular}{lll}
\hline Date & Low Tide UTC Time & High Tide UTC Time \\
\hline 07/12/2015 & $22: 00$ & $16: 00$ \\
$07 / 13 / 2015$ & $23: 00$ & $17: 00$ \\
$07 / 14 / 2015$ & $00: 00$ & $18: 00$ \\
$07 / 15 / 2015$ & $00: 00$ & $18: 00$ \\
$07 / 16 / 2015$ & $01: 00$ & $19: 00$ \\
$07 / 17 / 2015$ & $02: 00$ & $20: 00$ \\
$07 / 18 / 2015$ & $02: 00$ & $21: 00$ \\
$07 / 19 / 2015$ & $03: 00$ & $\underline{21: 00}$ \\
$07 / 20 / 2015$ & $04: 00$ & $\underline{10: 00}$ \\
$07 / 21 / 2015$ & $04: 00$ & $11: 00$ \\
$07 / 22 / 2015$ & $05: 00$ & $11: 00$ \\
$07 / 23 / 2015$ & $\underline{06: 00}$ & $12: 00$ \\
$07 / 24 / 2015$ & $\underline{19: 00}$ & $13: 00$ \\
$07 / 25 / 2015$ & $20: 00$ & $14: 00$ \\
$07 / 26 / 2015$ & $21: 00$ & $14: 00$ \\
$07 / 27 / 2015$ & $22: 00$ & $15: 00$ \\
$07 / 28 / 2015$ & $23: 00$ & $16: 00$ \\
$07 / 29 / 2015$ & $23: 00$ & $17: 00$ \\
$07 / 30 / 2015$ & $00: 00$ & $18: 00$ \\
$07 / 31 / 2015$ & $00: 00$ & $19: 00$ \\
\hline
\end{tabular}

Table A3. Tidal Wave Turning Points for February Months between 1995 and 2015 in Average, Time Lapse from Moon and Syzygy Events [4,3,6].

\begin{tabular}{|c|c|c|c|c|c|}
\hline Year, Month, Date and Time (Low, High Tide) & New Moon \pm Days & $1^{\text {st }} / 4 \pm$ Days & Full Moon \pm Days & $3^{\text {rd }} / 4 \pm$ Days & Syzygy \pm Days \\
\hline \multicolumn{6}{|l|}{$\ldots$} \\
\hline 1995/02/16 & $14: 00$ & 07:00 & & & \\
\hline $1995 / 02 / 17$ & 14:00 & 08:00 & & & \\
\hline 1995/02/18 & 15:00 & $\underline{21: 00}$ & & & \\
\hline 1995/02/19 & $\underline{16: 00}$ & $22: 00$ & +4.15 & -3.22 & $+55(\mathrm{P})$ \\
\hline $1995 / 02 / 20$ & $\overline{04: 00}$ & 23:00 & & & \\
\hline $1995 / 02 / 21$ & $\overline{05: 00}$ & 23:00 & & & \\
\hline \multicolumn{6}{|l|}{$\ldots$} \\
\hline $1996 / 02 / 20$ & 14:00 & 08:00 & & & \\
\hline 1996/02/21 & $\underline{15: 00}$ & $\underline{09: 00}$ & & & \\
\hline $1996 / 02 / 22$ & $\overline{03: 00}$ & $22: 00$ & +3.14 & -4.22 & $+42(\mathrm{~T})$ \\
\hline $1996 / 02 / 23$ & $\overline{04: 00}$ & $\overline{23: 00}$ & & & \\
\hline 1996/02/24 & 05:00 & 23:00 & & & \\
\hline \\
\hline \multicolumn{6}{|l|}{ 1997: NOT AVAILABLE } \\
\hline \multicolumn{6}{|l|}{$\ldots$} \\
\hline 1998/02/14 & $15: 00$ & 09:00 & & & \\
\hline $1998 / 02 / 15$ & $16: 00$ & $\underline{10: 00}$ & & & \\
\hline 1998/02/16 & $16: 00$ & $23: 00$ & & & \\
\hline 1998/02/17 & $\underline{17: 00}$ & $\overline{23: 00}$ & +6.27 & -1.10 & $+24(\mathrm{PU})$ \\
\hline 1998/02/18 & $\underline{05: 00}$ & 00:00 & & & \\
\hline 1998/02/19 & $\overline{06: 00}$ & 00:00 & & & \\
\hline \\
\hline \multicolumn{6}{|l|}{ 1999: NOT AVAILABLE } \\
\hline \multicolumn{6}{|l|}{. } \\
\hline $2000 / 02 / 21$ & $14: 00$ & 08:00 & & & \\
\hline $2000 / 02 / 22$ & $15: 00$ & $\underline{09: 00}$ & & & \\
\hline $2000 / 02 / 23$ & $16: 00$ & $\underline{22: 00}$ & & & \\
\hline $2000 / 02 / 24$ & $\underline{17: 00}$ & 23:00 & +5.02 & -2.35 & $-34(\mathrm{~T})$ \\
\hline $2000 / 02 / 25$ & $\underline{05: 00}$ & 00:00 & & & \\
\hline $2000 / 02 / 26$ & 06:00 & 00:00 & & & \\
\hline $2000 / 02 / 27$ & 07:00 & 01:00 & & & \\
\hline
\end{tabular}




\begin{tabular}{|c|c|c|c|c|c|}
\hline Year, Month, Date and Time (Low, High Tide) & New Moon \pm Days & $1^{\text {st }} / 4 \pm$ Days & Full Moon \pm Days & $3^{\text {rd }} / 4 \pm$ Days & Syzygy \pm Days \\
\hline $2001 / 02 / 09$ & $14: 00$ & 07:00 & & & \\
\hline $2001 / 02 / 10$ & 15:00 & $\underline{08: 00}$ & & & \\
\hline $2001 / 02 / 11$ & 15:00 & $\underline{22: 00}$ & & & \\
\hline 2001/02/12 & $\underline{16: 00}$ & 23:00 & +4.36 & -3.00 & $-34(\mathrm{~T})$ \\
\hline 2001/02/13 & 05:00 & 23:00 & & & \\
\hline $2001 / 02 / 14$ & $06: 00$ & 00:00 & & & \\
\hline $2001 / 02 / 15$ & 07:00 & 01:00 & & & \\
\hline \multicolumn{6}{|l|}{$\ldots$} \\
\hline \multicolumn{6}{|l|}{ 2002: NOT AVAILABLE } \\
\hline \multicolumn{6}{|l|}{$\ldots$} \\
\hline $2003 / 02 / 17$ & $13: 00$ & 07:00 & & & \\
\hline 2003/02/18 & 14:00 & 08:00 & & & \\
\hline 2003/02/19 & 15:00 & $\underline{21: 00}$ & & & \\
\hline $2003 / 02 / 20$ & 16:00 & $22: 00$ & +3.67 & -3.70 & $+85(\mathrm{~T})$ \\
\hline $2003 / 02 / 21$ & 17:00 & 23:00 & & & \\
\hline $2003 / 02 / 22$ & $\underline{05: 00}$ & 00:00 & & & \\
\hline $2003 / 02 / 23$ & 06:00 & 01:00 & & & \\
\hline \multicolumn{6}{|l|}{$\ldots$} \\
\hline $2004 / 02 / 22$ & 14:00 & 08:00 & & & \\
\hline $2004 / 02 / 23$ & $15: 00$ & $\underline{09: 00}$ & & & \\
\hline $2004 / 02 / 24$ & 16:00 & $\overline{22: 00}$ & +4.27 & -3.09 & $+70(\mathrm{~T})$ \\
\hline $2004 / 02 / 25$ & 04:00 & 23:00 & & & \\
\hline $2004 / 02 / 26$ & 05:00 & $23: 00$ & & & \\
\hline $2005 / 02 / 10$ & $14: 00$ & 08:00 & & & \\
\hline $2005 / 02 / 11$ & $15: 00$ & 09:00 & & & \\
\hline 2005/02/12 & $16: 00$ & $\underline{22: 00}$ & & & \\
\hline $2005 / 02 / 13$ & $\underline{17: 00}$ & $\overline{23: 00}$ & +4.77 & -2.60 & $+70(\mathrm{PU})$ \\
\hline $2005 / 02 / 14$ & $\underline{05: 00}$ & 23:00 & & & \\
\hline $2005 / 02 / 15$ & $\overline{06: 00}$ & 00:00 & & & \\
\hline \multicolumn{6}{|l|}{$\ldots$} \\
\hline 2006/02/15 & $15: 00$ & 08:00 & & & \\
\hline 2006/02/16 & $15: 00$ & $\underline{09: 00}$ & & & \\
\hline $2006 / 02 / 17$ & $16: 00$ & $\underline{22: 00}$ & & & \\
\hline $2006 / 02 / 18$ & $16: 00$ & $\overline{23: 00}$ & +5.46 & -1.90 & $+24(\mathrm{PU}-\mathrm{T})$ \\
\hline $2006 / 02 / 19$ & $\overline{05: 00}$ & 23:00 & & & \\
\hline $2006 / 02 / 20$ & $\overline{06: 00}$ & 00:00 & & & \\
\hline \multicolumn{6}{|l|}{$\ldots$} \\
\hline $2007 / 02 / 18$ & 13:00 & 07:00 & & & \\
\hline 2007/02/19 & $14: 00$ & $\underline{08: 00}$ & & & \\
\hline $2007 / 02 / 20$ & $15: 00$ & $\underline{21: 00}$ & & & \\
\hline $2007 / 02 / 21$ & 16:00 & $\overline{22: 00}$ & +3.99 & -3.38 & $+10(\mathrm{~T})$ \\
\hline $2007 / 02 / 22$ & $\overline{05: 00}$ & 23:00 & & & \\
\hline $2007 / 02 / 23$ & $06: 00$ & 00:00 & & & \\
\hline \\
\hline \multicolumn{6}{|l|}{ 2008: NOT AVAILABLE } \\
\hline \multicolumn{6}{|l|}{$\cdots$} \\
\hline $2009 / 02 / 10$ & 13:00 & 07:00 & & & \\
\hline $2009 / 02 / 11$ & $14: 00$ & $\underline{08: 00}$ & & & \\
\hline $2009 / 02 / 12$ & $15: 00$ & $\underline{21: 00}$ & & & \\
\hline $2009 / 02 / 13$ & 16:00 & $22: 00$ & +4.04 & -3.32 & $-4(\mathrm{PU})$ \\
\hline $2009 / 02 / 14$ & 04:00 & $23: 00$ & & & \\
\hline $2009 / 02 / 15$ & 05:00 & 00:00 & & & \\
\hline \multicolumn{6}{|l|}{$\ldots$} \\
\hline $2010 / 02 / 12$ & $12: 00$ & 06:00 & & & \\
\hline $2010 / 02 / 13$ & 13:00 & $\underline{06: 00}$ & & & \\
\hline $2010 / 02 / 14$ & 13:00 & $\underline{20: 00}$ & & & \\
\hline $2010 / 02 / 15$ & 14:00 & $\overline{08: 00}$ & & & \\
\hline
\end{tabular}




\begin{tabular}{|c|c|c|c|c|c|}
\hline Year, Month, Date and Time (Low, High Tide) & New Moon \pm Days & $1^{\text {st }} / 4 \pm$ Days & Full Moon \pm Days & $3^{\text {rd }} / 4 \pm$ Days & Syzygy \pm Days \\
\hline 2010/02/16 & 14:00 & $\underline{21: 00}$ & & & \\
\hline $2010 / 02 / 17$ & $15: 00$ & $\overline{21: 00}$ & +3.50 & -3.86 & $+129(\mathrm{P})$ \\
\hline 2010/02/18 & $\underline{16: 00}$ & 22:00 & & & \\
\hline 2010/02/19 & $\underline{04: 00}$ & 23:00 & & & \\
\hline $2010 / 02 / 20$ & $\overline{05: 00}$ & 23:00 & & & \\
\hline \multicolumn{6}{|l|}{$\ldots$} \\
\hline $2011 / 02 / 16$ & 11:00 & 05:00 & & & \\
\hline 2011/02/17 & $12: 00$ & $\underline{06: 00}$ & & & \\
\hline 2011/02/18 & 13:00 & $\overline{19: 00}$ & & & \\
\hline 2011/02/19 & 14:00 & $\overline{07: 00}$ & & & \\
\hline $2011 / 02 / 20$ & $14: 00$ & $\overline{08: 00}$ & +2.2 & -5.15 & $+115(\mathrm{~T})$ \\
\hline $2011 / 02 / 21$ & $\overline{03: 00}$ & $\overline{22: 00}$ & & & \\
\hline $2011 / 02 / 22$ & $\overline{04: 00}$ & $\overline{22: 00}$ & & & \\
\hline \multicolumn{6}{|l|}{$\ldots$} \\
\hline $2012 / 02 / 03$ & 09:00 & 03:00 & & & \\
\hline $2012 / 02 / 04$ & 10:00 & 04:00 & & & \\
\hline $2012 / 02 / 05$ & 11:00 & $\overline{17: 00}$ & & & \\
\hline 2012/02/06 & $12: 00$ & $\overline{05: 00}$ & & & \\
\hline $2012 / 02 / 07$ & $12: 00$ & $06: 00$ & & & \\
\hline $2012 / 02 / 08$ & 13:00 & $\underline{07: 00}$ & & & \\
\hline 2012/02/09 & 14:00 & $\underline{20: 00}$ & & & \\
\hline $2012 / 02 / 10$ & 15:00 & $\overline{21: 00}$ & +2.71 & -4.66 & $+115(\mathrm{P})$ \\
\hline $2012 / 02 / 11$ & 15:00 & $22: 00$ & & & \\
\hline $2012 / 02 / 12$ & $\overline{04: 00}$ & 23:00 & & & \\
\hline $2012 / 02 / 13$ & $05: 00$ & 23:00 & & & \\
\hline \multicolumn{6}{|l|}{$\ldots$} \\
\hline $2013 / 02 / 11$ & $14: 00$ & 07:00 & & & \\
\hline $2013 / 02 / 12$ & $14: 00$ & 08:00 & & & \\
\hline $2013 / 02 / 13$ & 15:00 & 09:00 & & & \\
\hline $2013 / 02 / 14$ & $\overline{04: 00}$ & $\underline{22: 00}$ & +3.86 & -3.51 & $+70(\mathrm{P})$ \\
\hline $2013 / 02 / 15$ & $\overline{05: 00}$ & $\overline{23: 00}$ & & & \\
\hline \multicolumn{6}{|l|}{$\ldots$} \\
\hline $2014 / 02 / 16$ & 14:00 & 08:00 & & & \\
\hline $2014 / 02 / 17$ & $15: 00$ & 08:00 & & & \\
\hline $2014 / 02 / 18$ & 15:00 & $\underline{09: 00}$ & & & \\
\hline $2014 / 02 / 19$ & $16: 00$ & $\overline{22: 00}$ & & & \\
\hline $2014 / 02 / 20$ & $\underline{17: 00}$ & $\overline{23: 00}$ & +5.71 & -1.66 & $+54(\mathrm{~T})$ \\
\hline $2014 / 02 / 21$ & $05: 00$ & $23: 00$ & & & \\
\hline $2014 / 02 / 22$ & $\overline{06: 00}$ & 00:00 & & & \\
\hline \multicolumn{6}{|l|}{$\ldots$} \\
\hline $2015 / 02 / 05$ & $14: 00$ & 08:00 & & & \\
\hline $2015 / 02 / 06$ & 15:00 & 08:00 & & & \\
\hline $2015 / 02 / 07$ & 15:00 & $\overline{21: 00}$ & & & \\
\hline $2015 / 02 / 08$ & 16:00 & $10: 00$ & & & \\
\hline 2015/02/09 & 17:00 & $\overline{23: 00}$ & & & \\
\hline $2015 / 02 / 10$ & $17: 00$ & $\overline{23: 00}$ & +6.74 & -0.63 & $+53(\mathrm{~T})$ \\
\hline $2015 / 02 / 11$ & 06:00 & 00:00 & & & \\
\hline $2015 / 02 / 12$ & $\overline{07: 00}$ & 00:00 & & & \\
\hline \multicolumn{6}{|l|}{$\ldots$} \\
\hline $2015 / 02 / 20$ & $14: 00$ & 08:00 & & & \\
\hline $2015 / 02 / 21$ & $15: 00$ & 09:00 & & & \\
\hline $2015 / 02 / 22$ & $16: 00$ & 22:00 & +3.55 & -3.82 & $+41(\mathrm{~T})$ \\
\hline $2015 / 02 / 23$ & 04:00 & 23:00 & & & \\
\hline $2015 / 02 / 24$ & 05:00 & 00:00 & & & \\
\hline
\end{tabular}

PU - Penumbral Eclipse, P - Partial Eclipse, T - Total Eclipse 
Table A4. Tidal Wave Turning Points for March Months between 1995 and 2015 in Average, Time Lapse from Moon and Syzygy Events [4,3,6].

\begin{tabular}{|c|c|c|c|c|c|}
\hline Year, Month, Date and Time (Low, High Tide) & New Moon \pm Days & $1^{\text {st }} / 4 \pm$ Days & Full Moon \pm Days & $3^{\text {rd }} / 4 \pm$ Days & Syzygy \pm Days \\
\hline 1995/03/13 & 10:00 & 04:00 & & & \\
\hline 1995/03/14 & 11:00 & $\underline{05: 00}$ & & & \\
\hline $1995 / 03 / 15$ & $12: 00$ & 18:00 & & & \\
\hline 1995/03/16 & 12:00 & 19:00 & & & \\
\hline $1995 / 03 / 17$ & 13:00 & 19:00 & +0.48 & -6.89 & $+29(\mathrm{P})$ \\
\hline $1995 / 03 / 18$ & 14:00 & 20:00 & & & \\
\hline 1995/03/19 & $\underline{15: 00}$ & 21:00 & & & \\
\hline $1995 / 03 / 20$ & $\underline{03: 00}$ & 22:00 & & & \\
\hline $1995 / 03 / 21$ & 04:00 & 22:00 & & & \\
\hline \multicolumn{6}{|l|}{$\ldots$} \\
\hline 1996/03/16 & 10:00 & 04:00 & & & \\
\hline 1996/03/17 & 11:00 & $\underline{05: 00}$ & & & \\
\hline 1996/03/18 & $12: 00$ & $\underline{18: 00}$ & & & \\
\hline 1996/03/19 & $\underline{13: 00}$ & 19:00 & +0.09 & -7.28 & $+16(\mathrm{~T})$ \\
\hline $1996 / 03 / 20$ & $\underline{01: 00}$ & $\underline{20: 00}$ & & & \\
\hline $1996 / 03 / 21$ & 02:00 & $\underline{08: 00}$ & & & \\
\hline $1996 / 03 / 22$ & 03:00 & $\underline{09: 00}$ & & & \\
\hline $1996 / 03 / 23$ & 04:00 & $\underline{22: 00}$ & & & \\
\hline 1996/03/24 & 05:00 & 23:00 & & & \\
\hline \multicolumn{6}{|l|}{ 1997: NOT AVAILABLE } \\
\hline $1998 / 03 / 25$ & $10: 00$ & 04:00 & & & \\
\hline $1998 / 03 / 26$ & 11:00 & $\underline{05: 00}$ & & & \\
\hline $1998 / 03 / 27$ & $12: 00$ & 18:00 & & & \\
\hline $1998 / 03 / 28$ & $\underline{13: 00}$ & 19:00 & +0.40 & -6.96 & $-15(\mathrm{PU})$ \\
\hline $1998 / 03 / 29$ & $\underline{01: 00}$ & $20: 00$ & & & \\
\hline $1998 / 03 / 30$ & 02:00 & 21:00 & & & \\
\hline \multirow{2}{*}{\multicolumn{6}{|c|}{ 1999: NOT AVAILABLE }} \\
\hline & & & & & \\
\hline $2000 / 03 / 19$ & $12: 00$ & 06:00 & & & \\
\hline $2000 / 03 / 20$ & 13:00 & $\underline{07: 00}$ & & & \\
\hline $2000 / 03 / 21$ & $\underline{14: 00}$ & $\underline{20: 00}$ & +1.38 & -5.98 & $-60(\mathrm{~T})$ \\
\hline $2000 / 03 / 22$ & $\underline{02: 00}$ & $21: 00$ & & & \\
\hline $2000 / 03 / 23$ & 03:00 & $22: 00$ & & & \\
\hline $2001 / 03 / 23$ & $12: 00$ & 18:00 & & & \\
\hline $2001 / 03 / 24$ & 13:00 & 19:00 & & & \\
\hline $2001 / 03 / 25$ & 13:00 & $\underline{20: 00}$ & & & \\
\hline $2001 / 03 / 26$ & $\underline{14: 00}$ & $\underline{08: 00}$ & +1.52 & -5.85 & $-76(T)$ \\
\hline $2001 / 03 / 27$ & $\underline{02: 00}$ & $\underline{21: 00}$ & & & \\
\hline $2001 / 03 / 28$ & 03:00 & $21: 00$ & & & \\
\hline \multicolumn{6}{|l|}{$\cdots$} \\
\hline \multicolumn{6}{|l|}{ 2002: NOT AVAILABLE } \\
\hline$\ldots$ & & & & & \\
\hline 2003/03/16 & $11: 00$ & 05:00 & & & \\
\hline 2003/03/17 & $12: 00$ & $\underline{06: 00}$ & & & \\
\hline $2003 / 03 / 18$ & 13:00 & $\underline{19: 00}$ & & & \\
\hline 2003/03/19 & $\underline{14: 00}$ & $20: 00$ & +1.14 & -6.23 & $+58(\mathrm{~T})$ \\
\hline $2003 / 03 / 20$ & $\underline{02: 00}$ & $21: 00$ & & & \\
\hline $2003 / 03 / 21$ & 03:00 & $21: 00$ & & & \\
\hline \multicolumn{6}{|l|}{$\ldots$} \\
\hline $2004 / 03 / 21$ & $13: 00$ & 07:00 & & & \\
\hline $2004 / 03 / 22$ & $\underline{14: 00}$ & $\underline{08: 00}$ & +1.63 & -5.73 & $+43(\mathrm{~T})$ \\
\hline $2004 / 03 / 23$ & $\underline{02: 00}$ & $\underline{21: 00}$ & & & \\
\hline $2004 / 03 / 24$ & 03:00 & $22: 00$ & & & \\
\hline
\end{tabular}




\begin{tabular}{|c|c|c|c|c|c|}
\hline Year, Month, Date and Time (Low, High Tide) & New Moon \pm Days & $\mathbf{1}^{\text {st }} / 4 \pm$ Days & Full Moon \pm Days & $3^{\text {rd }} / 4 \pm$ Days & Syzygy \pm Days \\
\hline \multicolumn{6}{|l|}{$\ldots$} \\
\hline $2005 / 03 / 24$ & 12:00 & 06:00 & & & \\
\hline $2005 / 03 / 25$ & 13:00 & $\underline{06: 00}$ & & & \\
\hline $2005 / 03 / 26$ & $\underline{13: 00}$ & $\overline{19: 00}$ & +0.66 & -6.70 & +29 (PU) \\
\hline $2005 / 03 / 27$ & $\underline{02: 00}$ & $\overline{20: 00}$ & & & \\
\hline $2005 / 03 / 28$ & $\overline{02: 00}$ & $21: 00$ & & & \\
\hline \multicolumn{6}{|l|}{$\ldots$} \\
\hline $2006 / 03 / 26$ & 10:00 & 04:00 & & & \\
\hline $2006 / 03 / 27$ & 11:00 & $\underline{05: 00}$ & & & \\
\hline $2006 / 03 / 28$ & 12:00 & $\overline{18: 00}$ & & & \\
\hline $2006 / 03 / 29$ & $\underline{13: 00}$ & $\overline{19: 00}$ & +0.11 & -7.26 & $-15(\mathrm{PU}-\mathrm{T})$ \\
\hline $2006 / 03 / 30$ & $\underline{01: 00}$ & $20: 00$ & & & \\
\hline $2006 / 03 / 31$ & $\overline{02: 00}$ & $21: 00$ & & & \\
\hline \multicolumn{6}{|l|}{$\ldots$} \\
\hline $2007 / 03 / 17$ & 11:00 & 05:00 & & & \\
\hline $2007 / 03 / 18$ & $12: 00$ & $\underline{06: 00}$ & & & \\
\hline 2007/03/19 & $\underline{13: 00}$ & $\overline{19: 00}$ & +0.42 & -6.94 & $-16(\mathrm{~T})$ \\
\hline $2007 / 03 / 20$ & $01: 00$ & $20: 00$ & & & \\
\hline $2007 / 03 / 21$ & $02: 00$ & $21: 00$ & & & \\
\hline \\
\hline \multicolumn{6}{|l|}{ 2008: NOT AVAILABLE } \\
\hline \multicolumn{6}{|l|}{$\ldots$} \\
\hline $2009 / 03 / 22$ & 10:00 & 03:00 & & & \\
\hline $2009 / 03 / 23$ & 11:00 & 04:00 & & & \\
\hline $2009 / 03 / 24$ & 11:00 & $\underline{05: 00}$ & & & \\
\hline $2009 / 03 / 25$ & $\underline{12: 00}$ & $\overline{18: 00}$ & -1.1 & +6.20 & $-44(\mathrm{PU})$ \\
\hline $2009 / 03 / 26$ & $\overline{00: 00}$ & $\overline{19: 00}$ & & & \\
\hline $2009 / 03 / 27$ & $\overline{01: 00}$ & 19:00 & & & \\
\hline \multicolumn{6}{|l|}{$\ldots$} \\
\hline $2010 / 03 / 13$ & 11:00 & 05:00 & & & \\
\hline $2010 / 03 / 14$ & $12: 00$ & 06:00 & & & \\
\hline $2010 / 03 / 15$ & $\overline{00: 00}$ & $\overline{19: 00}$ & -0.87 & +6.49 & $-74(\mathrm{PU})$ \\
\hline 2010/03/16 & $\overline{01: 00}$ & $\overline{20: 00}$ & & & \\
\hline 2010/03/17 & $\overline{14: 00}$ & 20:00 & & & \\
\hline 2010/03/18 & $\overline{15: 00}$ & $\overline{08: 00}$ & & & \\
\hline 2010/03/19 & $\overline{03: 00}$ & $\overline{21: 00}$ & & & \\
\hline $2010 / 03 / 20$ & $\overline{04: 00}$ & $\overline{22: 00}$ & & & \\
\hline \multicolumn{6}{|l|}{$\ldots$} \\
\hline 2011/03/16 & $10: 00$ & 03:00 & & & \\
\hline $2011 / 03 / 17$ & 11:00 & $\underline{04: 00}$ & & & \\
\hline $2011 / 03 / 18$ & 11:00 & $\overline{18: 00}$ & & & \\
\hline 2011/03/19 & $12: 00$ & $\overline{19: 00}$ & +7.11 & -0.25 & $-88(\mathrm{~T})$ \\
\hline $2011 / 03 / 20$ & 13:00 & 19:00 & & & \\
\hline $2011 / 03 / 21$ & $\overline{02: 00}$ & $20: 00$ & & & \\
\hline $2011 / 03 / 22$ & $\overline{03: 00}$ & $\underline{21: 00}$ & & & \\
\hline $2011 / 03 / 23$ & $\underline{20: 00}$ & $\underline{10: 00}$ & & & \\
\hline \multicolumn{6}{|l|}{$\ldots$} \\
\hline $2012 / 03 / 20$ & 11:00 & 05:00 & & & \\
\hline $2012 / 03 / 21$ & $12: 00$ & 06:00 & & & \\
\hline $2012 / 03 / 22$ & $\underline{13: 00}$ & $\overline{19: 00}$ & -0.06 & +7.30 & $+74(\mathrm{P})$ \\
\hline $2012 / 03 / 23$ & $\underline{01: 00}$ & $\overline{20: 00}$ & & & \\
\hline $2012 / 03 / 24$ & $\overline{02: 00}$ & $20: 00$ & & & \\
\hline \multicolumn{6}{|l|}{$\ldots$} \\
\hline $2013 / 03 / 22$ & 09:00 & 03:00 & & & \\
\hline $2013 / 03 / 23$ & 10:00 & $\underline{04: 00}$ & & & \\
\hline $2013 / 03 / 24$ & 11:00 & $\overline{17: 00}$ & & & \\
\hline $2013 / 03 / 25$ & 11:00 & $\overline{05: 00}$ & & & \\
\hline $2013 / 03 / 26$ & $12: 00$ & $18: 00$ & & & \\
\hline $2013 / 03 / 27$ & 13:00 & $\overline{19: 00}$ & +0.14 & -7.22 & $+29(\mathrm{P})$ \\
\hline
\end{tabular}




\begin{tabular}{|c|c|c|c|c|c|}
\hline Year, Month, Date and Time (Low, High Tide) & New Moon \pm Days & $1^{\text {st }} / 4 \pm$ Days & Full Moon \pm Days & $3^{\text {rd }} / 4 \pm$ Days & Syzygy \pm Days \\
\hline $2013 / 03 / 28$ & $\underline{01: 00}$ & 20:00 & & & \\
\hline 2013/03/29 & 02:00 & 20:00 & & & \\
\hline \multicolumn{6}{|l|}{$\ldots$} \\
\hline $2014 / 03 / 14$ & $12: 00$ & 05:00 & & & \\
\hline $2014 / 03 / 15$ & $12: 00$ & $\underline{06: 00}$ & & & \\
\hline 2014/03/16 & 13:00 & 19:00 & & & \\
\hline $2014 / 03 / 17$ & 13:00 & $\overline{20: 00}$ & +0.82 & -6.54 & $+29(\mathrm{~T})$ \\
\hline 2014/03/18 & $\underline{14: 00}$ & 20:00 & & & \\
\hline 2014/03/19 & $\underline{02: 00}$ & 21:00 & & & \\
\hline $2014 / 03 / 20$ & 03:00 & 22:00 & & & \\
\hline \multicolumn{6}{|l|}{$\ldots$} \\
\hline $2015 / 03 / 16$ & 09:00 & 02:00 & & & \\
\hline $2015 / 03 / 17$ & 10:00 & $\underline{03: 00}$ & & & \\
\hline 2015/03/18 & 11:00 & $\underline{17: 00}$ & & & \\
\hline $2015 / 03 / 19$ & $12: 00$ & $18: 00$ & -0.89 & +6.47 & $+16(\mathrm{~T})$ \\
\hline $2015 / 03 / 20$ & $\underline{13: 00}$ & 19:00 & & & \\
\hline $2015 / 03 / 21$ & $\underline{01: 00}$ & 20:00 & & & \\
\hline $2015 / 03 / 22$ & $02: 00$ & $\underline{21: 00}$ & & & \\
\hline $2015 / 03 / 23$ & 03:00 & $\overline{09: 00}$ & & & \\
\hline $2015 / 03 / 24$ & 04:00 & 22:00 & & & \\
\hline
\end{tabular}

PU - Penumbral Eclipse, P - Partial Eclipse, T - Total Eclipse

Table A5. Tidal Wave Turning Points for June Months between 1995 and 2015 in Average, Time Lapse from Moon and Syzygy Events [4,3,6].

\begin{tabular}{|c|c|c|c|c|c|}
\hline Year, Month, Date and Time (Low, High Tide) & New Moon \pm Days & Full Moon \pm Days & $1^{\text {st }} / 4 \pm$ Days & $3^{\text {rd }} / 4 \pm$ Days & Syzygy \pm Days \\
\hline $1995 / 06 / 16$ & 03:00 & $22: 00$ & & & \\
\hline $1995 / 06 / 17$ & 04:00 & 23:00 & & & \\
\hline 1995/06/18 & 05:00 & $\underline{11: 00}$ & & & \\
\hline 1995/06/19 & $06: 00$ & $\underline{00: 00}$ & & & \\
\hline $1995 / 06 / 20$ & 07:00 & 13:00 & +7.12 & -0.25 & $-66(\mathrm{P})$ \\
\hline $1995 / 06 / 21$ & $\underline{20: 00}$ & $\overline{14: 00}$ & & & \\
\hline $1995 / 06 / 22$ & 21:00 & 15:00 & & & \\
\hline \multicolumn{6}{|l|}{$\ldots$} \\
\hline 1996/06/21 & 04:00 & 23:00 & & & \\
\hline $1996 / 06 / 22$ & 05:00 & $\underline{23: 00}$ & & & \\
\hline $1996 / 06 / 23$ & 06:00 & $\underline{12: 00}$ & +7.22 & -0.15 & $-80(\mathrm{~T})$ \\
\hline 1996/06/24 & 07:00 & 13:00 & & & \\
\hline $1996 / 06 / 25$ & $\underline{07: 00}$ & 14:00 & & & \\
\hline $1996 / 06 / 26$ & $21: 00$ & $15: 00$ & & & \\
\hline 1996/06/27 & 22:00 & 15:00 & & & \\
\hline \multicolumn{6}{|l|}{$\ldots$} \\
\hline \multicolumn{6}{|l|}{ 1997: NOT AVAILABLE } \\
\hline \multicolumn{6}{|l|}{$\ldots$} \\
\hline 1998/06/14 & 04:00 & 22:00 & & & \\
\hline 1998/06/15 & 04:00 & $\underline{23: 00}$ & & & \\
\hline $1998 / 06 / 16$ & 05:00 & $\underline{12: 00}$ & & & \\
\hline 1998/06/17 & 06:00 & 13:00 & +7.06 & -0.30 & $+52(\mathrm{PU})$ \\
\hline 1998/06/18 & $\underline{07: 00}$ & 14:00 & & & \\
\hline 1998/06/19 & $\underline{21: 00}$ & 14:00 & & & \\
\hline $1998 / 06 / 20$ & 22:00 & $15: 00$ & & & \\
\hline \multicolumn{6}{|l|}{$\ldots$} \\
\hline \multicolumn{6}{|l|}{ 1999: NOT AVAILABLE } \\
\hline$\ldots$ & & & & & \\
\hline 2000/06/07 & 05:00 & 23:00 & & & \\
\hline 2000/06/08 & 06:00 & $\underline{00: 00}$ & & & \\
\hline 2000/06/09 & 07:00 & $\underline{13: 00}$ & & & \\
\hline $2000 / 06 / 10$ & 08:00 & $14: 00$ & +0.77 & -6.60 & $+36(\mathrm{~T})$ \\
\hline
\end{tabular}




\begin{tabular}{|c|c|c|c|c|c|}
\hline Year, Month, Date and Time (Low, High Tide) & New Moon \pm Days & Full Moon \pm Days & $1^{\text {st }} / 4 \pm$ Days & $3^{\text {rd }} / 4 \pm$ Days & Syzygy \pm Days \\
\hline $2000 / 06 / 11$ & $\underline{09: 00}$ & $15: 00$ & & & \\
\hline 2000/06/12 & $\underline{22: 00}$ & 16:00 & & & \\
\hline 2000/06/13 & 23:00 & 17:00 & & & \\
\hline \multicolumn{6}{|l|}{$\ldots$} \\
\hline 2001/06/12 & 05:00 & $12: 00$ & & & \\
\hline $2001 / 06 / 13$ & 06:00 & 13:00 & & & \\
\hline $2001 / 06 / 14$ & 07:00 & $\underline{01: 00}$ & & & \\
\hline $2001 / 06 / 15$ & $\underline{08: 00}$ & 14:00 & -6.16 & +1.21 & $+20(\mathrm{P})$ \\
\hline 2001/06/16 & $\underline{21: 00}$ & 15:00 & & & \\
\hline 2001/06/17 & 22:00 & 16:00 & & & \\
\hline \multicolumn{6}{|l|}{ 2002: NOT AVAILABLE } \\
\hline \multicolumn{6}{|l|}{. } \\
\hline 2003/06/19 & 05:00 & 23:00 & & & \\
\hline $2003 / 06 / 20$ & 06:00 & $\underline{00: 00}$ & & & \\
\hline $2003 / 06 / 21$ & 06:00 & $\underline{13: 00}$ & +6.65 & -0.72 & $-36(\mathrm{~T})$ \\
\hline 2003/06/22 & 07:00 & 14:00 & & & \\
\hline $2003 / 06 / 23$ & $\underline{08: 00}$ & 14:00 & & & \\
\hline $2003 / 06 / 24$ & $\underline{22: 00}$ & 15:00 & & & \\
\hline $2003 / 06 / 25$ & 22:00 & 16:00 & & & \\
\hline \multicolumn{6}{|l|}{$\cdots$} \\
\hline $2004 / 06 / 22$ & 04:00 & $22: 00$ & & & \\
\hline $2004 / 06 / 23$ & 05:00 & 23:00 & & & \\
\hline $2004 / 06 / 24$ & 05:00 & $\underline{12: 00}$ & & & \\
\hline $2004 / 06 / 25$ & 06:00 & $13: 00+7.27$ & -0.10 & $-52(\mathrm{~T})$ & \\
\hline $2004 / 06 / 26$ & 07:00 & $13: 00$ & & & \\
\hline $2004 / 06 / 27$ & $\underline{08: 00}$ & $14: 00$ & & & \\
\hline $2004 / 06 / 28$ & $\underline{21: 00}$ & $15: 00$ & & & \\
\hline $2004 / 06 / 29$ & $22: 00$ & 16:00 & & & \\
\hline \multicolumn{6}{|l|}{$\ldots$} \\
\hline $2005 / 06 / 11$ & 04:00 & $22: 00$ & & & \\
\hline $2005 / 06 / 12$ & 05:00 & $\underline{23: 00}$ & & & \\
\hline $2005 / 06 / 13$ & 05:00 & $\underline{12: 00}$ & & & \\
\hline $2005 / 06 / 14$ & 06:00 & $12: 00$ & +7.33 & -0.03 & $-51(\mathrm{PU})$ \\
\hline $2005 / 06 / 15$ & 07:00 & 13:00 & & & \\
\hline $2005 / 06 / 16$ & $\underline{08: 00}$ & 14:00 & & & \\
\hline $2005 / 06 / 17$ & $\underline{21: 00}$ & 15:00 & & & \\
\hline $2005 / 06 / 18$ & $22: 00$ & $15: 00$ & & & \\
\hline \multicolumn{6}{|l|}{$\ldots$} \\
\hline $2006 / 06 / 15$ & 03:00 & 22:00 & & & \\
\hline $2006 / 06 / 16$ & 04:00 & 23:00 & & & \\
\hline $2006 / 06 / 17$ & 05:00 & $\underline{23: 00}$ & & & \\
\hline 2006/06/18 & $\underline{06: 00}$ & $\underline{12: 00}$ & +6.49 & -0.87 & $+81(\mathrm{P})$ \\
\hline 2006/06/19 & $\underline{20: 00}$ & 13:00 & & & \\
\hline $2006 / 06 / 20$ & $21: 00$ & 14:00 & & & \\
\hline \multicolumn{6}{|l|}{$\ldots$} \\
\hline $2007 / 06 / 19$ & 04:00 & 22:00 & & & \\
\hline $2007 / 06 / 20$ & 05:00 & $\underline{23: 00}$ & & & \\
\hline $2007 / 06 / 21$ & 06:00 & $\underline{12: 00}$ & & & \\
\hline $2007 / 06 / 22$ & 06:00 & 13:00 & +7.11 & -0.25 & $+67(\mathrm{~T})$ \\
\hline $2007 / 06 / 23$ & $\underline{07: 00}$ & 14:00 & & & \\
\hline $2007 / 06 / 24$ & $\underline{21: 00}$ & 14:00 & & & \\
\hline $2007 / 06 / 25$ & $22: 00$ & $15: 00$ & & & \\
\hline \multicolumn{6}{|l|}{ 2008: NOT AVAILABLE } \\
\hline \multicolumn{6}{|l|}{ - } \\
\hline $2009 / 06 / 25$ & $3: 00$ & 21:00 & & & \\
\hline $2009 / 06 / 26$ & 3:00 & $\underline{22: 00}$ & & & \\
\hline $2009 / 06 / 27$ & $4: 00$ & $\underline{11: 00}$ & & & \\
\hline
\end{tabular}




\begin{tabular}{|c|c|c|c|c|c|}
\hline Year, Month, Date and Time (Low, High Tide) & New Moon \pm Days & Full Moon \pm Days & $1^{\text {st }} / 4 \pm$ Days & $3^{\text {rd } / 4 \pm \text { Days }}$ & Syzygy \pm Days \\
\hline $2009 / 06 / 28$ & 05:00 & $12: 00$ & +5.39 & -1.98 & $+9(\mathrm{PU})$ \\
\hline $2009 / 06 / 29$ & $\underline{06: 00}$ & 12:00 & & & \\
\hline $2009 / 06 / 30$ & $\underline{20: 00}$ & 13:00 & & & \\
\hline 2009/07/01 & 21:00 & 14:00 & & & \\
\hline $2010 / 06 / 15$ & 03:00 & 21:00 & & & \\
\hline $2010 / 06 / 16$ & 04:00 & $\underline{22: 00}$ & & & \\
\hline $2010 / 06 / 17$ & 05:00 & $\underline{11: 00}$ & & & \\
\hline $2010 / 06 / 18$ & 05:00 & 12:00 & +5.74 & -1.63 & $+8(\mathrm{P})$ \\
\hline $2010 / 06 / 19$ & 06:00 & 13:00 & & & \\
\hline $2010 / 06 / 20$ & $\underline{07: 00}$ & 14:00 & & & \\
\hline $2010 / 06 / 21$ & $\underline{21: 00}$ & 15:00 & & & \\
\hline $2010 / 06 / 22$ & $\overline{22: 00}$ & 16:00 & & & \\
\hline \multicolumn{6}{|l|}{$\ldots$} \\
\hline 2011/06/18 & 02:00 & 21:00 & & & \\
\hline $2011 / 06 / 19$ & 03:00 & $\underline{22: 00}$ & & & \\
\hline $2011 / 06 / 20$ & 04:00 & $\underline{10: 00}$ & & & \\
\hline $2011 / 06 / 21$ & 05:00 & $11: 00$ & & & \\
\hline $2011 / 06 / 22$ & 06:00 & $12: 00$ & +6.28 & -1.09 & $-7(T)$ \\
\hline $2011 / 06 / 23$ & 06:00 & 13:00 & & & \\
\hline $2011 / 06 / 24$ & $\underline{07: 00}$ & $14: 00$ & & & \\
\hline $2011 / 06 / 25$ & $\overline{21: 00}$ & 14:00 & & & \\
\hline $2011 / 06 / 26$ & $\overline{21: 00}$ & 15:00 & & & \\
\hline \multicolumn{6}{|l|}{$\ldots$} \\
\hline $2012 / 06 / 22$ & 03:00 & 21:00 & & & \\
\hline $2012 / 06 / 23$ & 03:00 & $\underline{22: 00}$ & & & \\
\hline $2012 / 06 / 24$ & 04:00 & $10: 00$ & & & \\
\hline $2012 / 06 / 25$ & 05:00 & $\overline{11: 00}$ & & & \\
\hline $2012 / 06 / 26$ & 06:00 & $12: 00+6.49$ & -0.87 & $-22(\mathrm{P})$ & \\
\hline $2012 / 06 / 27$ & 06:00 & $13: 00$ & & & \\
\hline $2012 / 06 / 28$ & $\overline{20: 00}$ & 14:00 & & & \\
\hline $2012 / 06 / 29$ & $21: 00$ & $14: 00$ & & & \\
\hline \multicolumn{6}{|l|}{$\ldots$} \\
\hline $2013 / 06 / 12$ & 03:00 & 22:00 & & & \\
\hline $2013 / 06 / 13$ & 04:00 & $\underline{22: 00}$ & & & \\
\hline $2013 / 06 / 14$ & 05:00 & $11: 00$ & & & \\
\hline $2013 / 06 / 15$ & 05:00 & $\overline{12: 00}$ & +6.54 & -0.83 & $-21(\mathrm{PU})$ \\
\hline $2013 / 06 / 16$ & 06:00 & $12: 00$ & & & \\
\hline $2013 / 06 / 17$ & $\underline{07: 00}$ & $13: 00$ & & & \\
\hline $2013 / 06 / 18$ & $\overline{20: 00}$ & 14:00 & & & \\
\hline $2013 / 06 / 19$ & $\overline{21: 00}$ & 15:00 & & & \\
\hline \multicolumn{6}{|l|}{$\ldots$} \\
\hline $2013 / 06 / 25$ & 02:00 & 20:00 & & & \\
\hline $2013 / 06 / 26$ & 03:00 & $\underline{21: 00}$ & & & \\
\hline $2013 / 06 / 27$ & 04:00 & $10: 00$ & & & \\
\hline $2013 / 06 / 28$ & 05:00 & $11: 00$ & +4.72 & -2.64 & $-34(\mathrm{PU})$ \\
\hline $2013 / 06 / 29$ & $\underline{06: 00}$ & $12: 00$ & & & \\
\hline $2013 / 06 / 30$ & $\overline{19: 00}$ & 13:00 & & & \\
\hline \multicolumn{6}{|l|}{$\ldots$} \\
\hline $2014 / 06 / 16$ & 03:00 & $22: 00$ & & & \\
\hline $2014 / 06 / 17$ & 04:00 & 23:00 & & & \\
\hline $2014 / 06 / 18$ & 05:00 & $\overline{11: 00}$ & & & \\
\hline $2014 / 06 / 19$ & 06:00 & $12: 00$ & +6.07 & -1.30 & $-65(\mathrm{~T})$ \\
\hline $2014 / 06 / 20$ & 07:00 & 13:00 & & & \\
\hline $2014 / 06 / 21$ & 08:00 & 14:00 & & & \\
\hline $2014 / 06 / 22$ & $\underline{21: 00}$ & 15:00 & & & \\
\hline $2014 / 06 / 23$ & $\overline{22: 00}$ & 16:00 & & & \\
\hline \multicolumn{6}{|l|}{$\ldots$} \\
\hline
\end{tabular}




\begin{tabular}{|c|c|c|c|c|c|}
\hline Year, Month, Date and Time (Low, High Tide) & New Moon \pm Days & Full Moon \pm Days & $1^{\text {st }} / 4 \pm$ Days & $3^{\text {rd }} / 4 \pm$ Days & Syzygy \pm Days \\
\hline $2015 / 06 / 21$ & 04:00 & $\underline{23: 00}$ & & & \\
\hline $2015 / 06 / 22$ & 05:00 & $\underline{11: 00}$ & & & \\
\hline $2015 / 06 / 23$ & 06:00 & 12:00 & +6.66 & -0.71 & $-80(\mathrm{~T})$ \\
\hline $2015 / 06 / 24$ & 06:00 & 13:00 & & & \\
\hline $2015 / 06 / 25$ & $\underline{07: 00}$ & 14:00 & & & \\
\hline $2015 / 06 / 26$ & $\underline{21: 00}$ & 14:00 & & & \\
\hline $2015 / 06 / 27$ & 22:00 & $15: 00$ & & & \\
\hline
\end{tabular}

PU - Penumbral Eclipse, P - Partial Eclipse, T - Total Eclipse

Table A6. Magnitude 8.0 and Greater Earthquakes since 1900 [5].

\begin{tabular}{|c|c|c|}
\hline Date in UTC - Time & Latitude, Longitude, & Magnitude (Region) \\
\hline 1902/06/11 05:00 & $+050.00,+148.00$ & 8.0 Sea of Okhotsk \\
\hline 1903/01/04 05:07 & $-020.00,-175.00$ & 8.0 Tonga \\
\hline 1903/08/11 04:32 & $+036.36,+022.97$ & 8.3 Southern Greece \\
\hline 1905/07/09 09:40 & $+049.00,+099.00$ & 8.4 Mongolia \\
\hline 1905/07/23 02:46 & $+049.00,+098.00$ & 8.4 Central Mongolia \\
\hline 1906/01/31 15:36 & $+001.00,-081.50$ & 8.8 Colombia-Ecuador \\
\hline 1906/08/17 00:40 & $-033.00,-072.00$ & 8.2 Valparaiso, Chile \\
\hline $1907 / 10 / 2104: 23$ & $+038.00,+069.00$ & 8.0 Afghanistan \\
\hline 1908/12/12 12:08 & $-014.00,-078.00$ & 8.2 off the Coast of Central Peru \\
\hline 1911/06/15 14:26 & $+028.00,+130.00$ & 8.1 Ryukyu Islands, Japan \\
\hline $1914 / 05 / 2614: 22$ & $-002.00,+137.00$ & 8.0 West New Guinea \\
\hline 1915/05/01 05:00 & $+047.00,+155.00$ & 8.0 Kurile Islands \\
\hline 1917/05/01 18:26 & $-029.00,-177.00$ & 8.0 Kermadec Islands, New Zealand \\
\hline 1917/06/26 05:49 & $-015.00,-173.00$ & 8.4 Tonga \\
\hline 1918/08/15 12:18 & $+005.65,+123.56$ & 8.0 Celebes Sea \\
\hline 1918/09/07 17:16 & $+045.50,+151.50$ & 8.2 Kuril Islands \\
\hline 1919/04/30 07:17 & $-019.82,-172.21$ & 8.2 Tonga Region \\
\hline 1920/06/05 04:21 & $+023.50,+122.00$ & 8.0 Taiwan Region \\
\hline $1920 / 09 / 2014: 39$ & $-020.00,+168.00$ & 8.0 Loyalty Islands \\
\hline 1922/11/11 04:32 & $-028.55,-070.75$ & 8.5 Chile-Argentina Border \\
\hline 1923/02/03 16:01 & $+054.00,+161.00$ & 8.5 Kamchatka \\
\hline $1924 / 04 / 1416: 20$ & $+007.02,+125.95$ & 8.3 Mindanao, Philippines \\
\hline 1928/06/17 03:19 & $+016.33,-096.70$ & 8.0 Oaxaca, Mexico \\
\hline 1931/08/10 21:18 & $+047.10,+089.80$ & 8.0 northern Xinjiang, China \\
\hline 1932/06/03 10:36 & $+019.84,-103.99$ & 8.1 Jalisco, Mexico \\
\hline 1933/03/02 17:31 & $+039.22,+144.62$ & 8.4 Sanriku, Japan \\
\hline 1934/01/15 08:43 & $+027.55,+087.09$ & 8.1 Bihar, India \\
\hline 1938/02/01 19:04 & $-005.05,+131.62$ & 8.5 Banda Sea \\
\hline 1938/11/10 20:18 & $+055.33,-158.37$ & 8.2 Shumagin Islands, Alaska \\
\hline $1939 / 04 / 3002: 55$ & $-010.50,+158.50$ & 8.0 Solomon Islands \\
\hline $1940 / 05 / 2416: 33$ & $-010.50,-077.00$ & 8.2 near the Coast of Central Peru \\
\hline $1941 / 11 / 2518: 03$ & $+037.17,-018.96$ & 8.2 Azores-Cape St.Vincent Ridge \\
\hline $1942 / 08 / 2422: 50$ & $-015.00,-076.00$ & 8.2 Off the Coast of Central Peru \\
\hline 1943/04/06 16:07 & $-030.75,-072.00$ & 8.2 off the Coast of Coquimbo, Chile \\
\hline 1944/12/07 04:35 & $+033.75,+136.00$ & 8.1 Tonankai, Japan \\
\hline $1945 / 11 / 2721: 57$ & $+024.50,+063.00$ & 8.0 off the Coast of Pakistan \\
\hline 1946/04/01 12:28 & $+052.75,-163.50$ & 8.1 Unimak Islands, Alaska \\
\hline 1946/08/04 17:51 & $+019.25,-069.00$ & 8.0 Dominican Republic \\
\hline 1946/12/20 19:19 & $+032.50,+134.50$ & 8.1 Nankaido, Japan \\
\hline 1948/01/24 17:46 & $+010.50,+122.00$ & 8.2 Panay, Philippines \\
\hline 1949/08/22 04:01 & $+053.62,-133.27$ & 8.1 Queen Charlotte Island, B.C., Canada \\
\hline 1950/08/15 14:09 & $+028.50,+096.50$ & 8.6 Assam-Tibet \\
\hline 1952/03/04 01:22 & $+042.50,+143.00$ & 8.1 Hokkaido, Japan Region \\
\hline 1952/11/04 16:58 & $+052.76,+160.06$ & 9.0 Kamchatka, Russia \\
\hline 1957/03/09 14:22 & $+051.56,-175.39$ & 8.6 Andreanof Islands, Alaska \\
\hline 1957/12/04 03:37 & $+045.15,+099.21$ & 8.1 Gobi-Altai, Mongolia \\
\hline
\end{tabular}




\begin{tabular}{|c|c|c|}
\hline Date in UTC - Time & Latitude, Longitude, & Magnitude (Region) \\
\hline $1958 / 11 / 0622: 58$ & $+044.32,+148.62$ & 8.3 Kuril Islands \\
\hline 1959/05/04 07:15 & $+053.35,+159.64$ & 8.2 near the East Coast of Kamchatka \\
\hline 1960/05/22 19:11 & $-038.29,-073.05$ & 9.5 Chile \\
\hline 1963/10/13 05:17 & $+044.90,+149.60$ & 8.5 Kuril Islands \\
\hline $1964 / 03 / 28$ 03:36 & $+061.02,-147.65$ & 9.2 Prince William Sound, Alaska \\
\hline 1965/02/04 05:01 & $+051.21,-178.50$ & 8.7 Rat Islands, Alaska \\
\hline 1966/10/17 21:41 & $-010.80,-078.68$ & 8.1 near the Coast of Central Peru \\
\hline 1968/05/16 00:49 & $+040.90,+143.34$ & 8.2 off the East Coast of Honshu, Japan \\
\hline 1969/08/11 21:27 & $+043.47,+147.81$ & 8.2 Kuril Islands \\
\hline 1970/07/31 17:08 & $-001.49,-072.56$ & 8.0 Colombia \\
\hline 1971/01/10 07:17 & $-003.13,+139.69$ & 8.1 Papua, Indonesia \\
\hline 1974/10/03 14:21 & $-012.25,-077.52$ & 8.1 near the Coast of Central Peru \\
\hline 1976/08/16 16:11 & $+006.29,+124.09$ & 8.0 Mindanao, Philippines \\
\hline 1977/06/22 12:08 & $-022.87,-175.90$ & 8.1 Tonga Region \\
\hline 1977/08/19 06:08 & $-011.08,+118.46$ & 8.3 South of Sumbawa, Indonesia \\
\hline 1979/12/12 07:59 & $+001.59,-079.35$ & 8.1 near the Coast of Ecuador \\
\hline 1985/03/03 22:47 & $-033.13,-071.87$ & 8.0 Offshore Valparaiso, Chile \\
\hline 1985/09/19 13:17 & $+018.19,-102.53$ & 8.0 Michoacan, Mexico \\
\hline 1986/05/07 22:47 & $+051.52,-174.77$ & 8.0 Andrean of Islands, Aleutian Islands, Alaska \\
\hline $1989 / 05 / 2310: 54$ & $-052.34,+160.56$ & 8.1 Macquarie Island Region \\
\hline 1994/06/09 00:33 & $-013.84,-067.55$ & 8.2 La Paz, Bolivia \\
\hline 1994/10/04 13:22 & $+043.77,+147.32$ & 8.3 Kuril Islands \\
\hline 1995/07/30 05:11 & $-023.34,-070.29$ & 8.0 Near Coast of Northern Chile \\
\hline 1995/10/09 15:35 & $+019.05,-104.20$ & 8.0 Near Coast of Jalisco, Mexico \\
\hline 1996/02/17 05:59 & $-000.89,+136.95$ & 8.2 Irian Jaya Region, Indonesia \\
\hline 1998/03/25 03:12 & $-062.87,+149.52$ & 8.1 Balleny Islands Region \\
\hline 2000/11/16 04:54 & $-003.98,+152.16$ & 8.0 New Ireland Region, Papua New Guinea \\
\hline 2001/06/23 20:33 & $-016.26,-73.64$ & 8.4 near the coast of Southern Peru \\
\hline 2003/09/25 19:50 & $+041.81,+143.91$ & 8.3 Hokkaido, Japan Region \\
\hline $2004 / 12 / 2314: 59$ & $-049.31,+161.34$ & 8.1 North of Macquarie Island \\
\hline 2004/12/26 00:58 & $+003.29,+095.98$ & 9.1 off the West Coast of Northern Sumatra \\
\hline 2005/03/28 16:09 & $+002.07,+097.01$ & 8.6 Northern Sumatra, Indonesia \\
\hline 2006/05/03 15:26 & $-020.18,-174.12$ & 8.0 Tonga \\
\hline $2006 / 11 / 1511: 14$ & $+046.59,+153.22$ & 8.3 Kuril Islands \\
\hline 2007/01/13 04:23:21 & $+046.24,+154.52$ & 8.1 East of the Kuril Islands \\
\hline 2007/04/01 20:39:58 & $-008.46,+157.04$ & 8.1 Solomon Islands \\
\hline 2007/08/15 23:40:57 & $-013.38,-076.60$ & 8.0 near the Coast of Central Peru \\
\hline 2007/09/12 11:10:26 & $-004.43,+101.36$ & 8.5 Southern Sumatra, Indonesia \\
\hline 2009/09/29 17:48:10 & $-015.48,-172.09$ & 8.1 Samoa Islands Region \\
\hline 2010/02/27 06:34:14 & $-035.84,-072.71$ & 8.8 Offshore Maule, Chile \\
\hline 2011/03/11 05:46:23 & $+038.32,+142.36$ & 9.0 near the East Coast of Honshu, Japan \\
\hline 2012/04/11 08:38:37 & $+002.31,+093.06$ & 8.6 off the West Coast of Northern Sumatra \\
\hline 2012/04/11 10:43:09 & $+000.77,+092.45$ & 8.2 off the West Coast of Northern Sumatra \\
\hline
\end{tabular}

Table A7. Magnitude 8.0 and Greater Earthquakes since 1900 with a Clue of Time Lapse from Moon Events [5,3].

\begin{tabular}{|c|c|c|c|c|}
\hline Month and Date & New Moon \pm Days & $1^{\text {st }}$ Quarter \pm Days & Full Moon \pm Days & $3^{\text {rd }}$ Quarter \pm Days \\
\hline 1902/06/11 05:00 & +4.95 & -2.42 & & \\
\hline 1903/01/04 05:07 & +5.32 & -2.05 & & \\
\hline 1903/08/11 04:32 & & & +2.81 & -4.55 \\
\hline 1905/07/09 09:40 & +6.65 & -0.71 & & \\
\hline 1905/07/23 02:46 & & & +6.46 & -0.90 \\
\hline 1906/01/31 15:36 & +6.93 & -0.44 & & \\
\hline 1906/08/17 00:40 & -3.03 & & & +4.34 \\
\hline 1907/10/21 04:23 & & & -0.20 & +7.17 \\
\hline 1908/12/12 12:08 & & & +4.59 & -2.77 \\
\hline 1911/06/15 14:26 & & & +3.69 & -3.68 \\
\hline $1914 / 05 / 2614: 22$ & +1.49 & & -5.88 & \\
\hline 1915/05/01 05:00 & & & +1.61 & -5.76 \\
\hline 1917/05/01 18:26 & & +2.02 & -5.34 & \\
\hline 1917/06/26 05:49 & +6.69 & -0.67 & & \\
\hline
\end{tabular}




\begin{tabular}{|c|c|c|c|c|}
\hline Month and Date & New Moon \pm Days & $1^{\text {st }}$ Quarter \pm Days & Full Moon \pm Days & $3^{\text {rd }}$ Quarter \pm Days \\
\hline 1918/08/15 12:18 & & +0.67 & -6.69 & \\
\hline 1918/09/07 17:16 & +2.27 & -5.10 & & \\
\hline 1919/04/30 07:17 & +0.07 & -7.30 & & \\
\hline 1920/06/05 04:21 & & & +3.46 & -3.91 \\
\hline 1920/09/20 14:39 & +8.07 & +0.70 & & \\
\hline $1922 / 11 / 1104: 32$ & & & +6.41 & -0.96 \\
\hline $1923 / 02 / 03 \quad 16: 01$ & & & +2.00 & -5.37 \\
\hline $1924 / 04 / 14 \quad 16: 20$ & & +2.46 & -4.91 & \\
\hline 1928/06/17 03:19 & -0.72 & +6.64 & & \\
\hline 1931/08/10 21:18 & -2.96 & & & +4.41 \\
\hline $1932 / 06 / 03 \quad 10: 36$ & -0.94 & & & +6.42 \\
\hline $1933 / 03 / 02 \quad 17: 31$ & +6.19 & -1.17 & & \\
\hline $1934 / 01 / 15$ 08:43 & -0.20 & +7.17 & & \\
\hline 1938/02/01 19:04 & +1.22 & -6.14 & & \\
\hline $1938 / 11 / 1020: 18$ & & & +2.91 & -4.46 \\
\hline 1939/04/30 02:55 & & +3.86 & -3.51 & \\
\hline $1940 / 05 / 2416: 33$ & & +3.12 & -4.24 & \\
\hline 1941/11/25 18:03 & +6.74 & -0.62 & & \\
\hline $1942 / 08 / 2422: 50$ & & +6.16 & -1.20 & \\
\hline 1943/04/06 16:07 & +1.75 & -5.61 & & \\
\hline 1944/12/07 04:35 & & & +7.15 & -0.21 \\
\hline $1945 / 11 / 2721: 57$ & -6.83 & & & +0.53 \\
\hline 1946/04/01 12:28 & -0.67 & & & +6.70 \\
\hline $1946 / 08 / 0417: 51$ & +7.24 & -0.12 & & \\
\hline 1946/12/20 19:19 & -2.74 & & & +4.63 \\
\hline 1948/01/24 17:46 & & +5.81 & -1.55 & \\
\hline $1949 / 08 / 22$ 04:01 & -1.99 & & & +5.37 \\
\hline 1950/08/15 14:09 & +1.88 & -5.48 & & \\
\hline 1952/03/04 01:22 & & -0.32 & -7.70 & \\
\hline $1952 / 11 / 0416: 58$ & & & +2.74 & -4.63 \\
\hline 1957/03/09 14:22 & +7.92 & +0.54 & & \\
\hline $1957 / 12 / 0403: 37$ & & +4.26 & -3.11 & \\
\hline $1958 / 11 / 0622: 58$ & -4.31 & & & +3.05 \\
\hline 1959/05/04 07:15 & -3.53 & & & +3.83 \\
\hline $1960 / 05 / 22 \quad 19: 11$ & -2.71 & & & +4.65 \\
\hline $1963 / 10 / 13$ 05:17 & -4.30 & & & +3.06 \\
\hline $1964 / 03 / 28$ 03:36 & & -7.34 & +0.03 & \\
\hline 1965/02/04 05:01 & +2.51 & -4.85 & & \\
\hline 1966/10/17 21:41 & +3.74 & -3.63 & & \\
\hline 1968/05/16 00:49 & & & +3.48 & -3.88 \\
\hline $1969 / 08 / 1121: 27$ & -1.32 & & & +6.04 \\
\hline 1970/07/31 17:08 & -1.53 & & & +5.83 \\
\hline 1971/01/10 07:17 & & +6.12 & & -1.25 \\
\hline $1974 / 10 / 03 \quad 14: 21$ & & & +2.15 & -5.22 \\
\hline $1976 / 08 / 16 \quad 16: 11$ & & & +6.68 & -0.68 \\
\hline 1977/06/22 12:08 & +5.73 & -1.63 & & \\
\hline $1977 / 08 / 1906: 08$ & +4.35 & -3.01 & & \\
\hline $1979 / 12 / 1207: 59$ & -7.01 & & & +0.35 \\
\hline 1985/03/03 22:47 & & +4.23 & -3.14 & \\
\hline 1985/09/19 13:17 & +4.74 & -2.62 & & \\
\hline 1986/05/07 22:47 & -0.97 & & & +6.40 \\
\hline $1989 / 05 / 23 \quad 10: 54$ & & +2.69 & -4.68 & \\
\hline 1994/06/09 00:33 & -0.32 & & & +7.04 \\
\hline 1994/10/04 13:22 & -0.60 & & & +6.76 \\
\hline 1995/07/30 05:11 & +2.58 & -4.79 & & \\
\hline 1995/10/09 15:35 & & & +0.98 & -6.38 \\
\hline $1996 / 02 / 1705: 59$ & -1.73 & & & +5.64 \\
\hline 1998/03/25 03:12 & -3.00 & & & +4.37 \\
\hline 2000/11/16 04:54 & & & +4.31 & -3.05 \\
\hline $2001 / 06 / 2320: 33$ & +2.35 & & -5.01 & \\
\hline 2003/09/25 19:50 & -0.30 & & & +7.07 \\
\hline $2004 / 12 / 2314: 59$ & & +4.37 & -3.00 & \\
\hline $2004 / 12 / 2600: 58$ & & +6.78 & -0.58 & \\
\hline $2005 / 03 / 28 \quad 16: 09$ & & & +2.79 & -4.57 \\
\hline $2006 / 05 / 03 \quad 15: 26$ & +5.81 & -1.55 & & \\
\hline 2006/11/15 11:14 & -5.45 & & & +1.91 \\
\hline $2007 / 01 / 1304: 23$ & -5.98 & & & +1.39 \\
\hline
\end{tabular}




\begin{tabular}{lllll}
\hline Month and Date & New Moon \pm Days & $\mathbf{1}^{\text {st }}$ Quarter \pm Days & Full Moon \pm Days & $\mathbf{3}^{\text {rd }}$ Quarter \pm Days \\
\hline 2007/04/01 20:39 & & +6.51 & -0.85 & \\
$2007 / 08 / 1523: 40$ & +3.025 & -4.34 & & \\
2007/09/12 11:10 & +0.93 & -6.44 & -4.51 & \\
2009/09/29 17:48 & & +2.85 & -1.41 & -2.81 \\
2010/02/27 06:34 & & +5.95 & & -2.73 \\
2011/03/11 05:46 & +6.37 & -1.00 & +4.55 & \\
2012/04/11 08:38 & & & +4.64 & \\
$2012 / 04 / 1110: 43$ & & & & \\
\hline
\end{tabular}

Table A8. Magnitude 8.0 and Greater Earthquakes since 1900 with a Clue of Time Lapse from Syzygy Events [5,6,3].

\begin{tabular}{|c|c|c|}
\hline Date in UTC - Time & Magnitude (Region) & Time Lapse from Syzygy Events \pm Days \\
\hline 1902/06/11 05:00 & 8.0 Sea of Okhotsk & $-50(\mathrm{~T})$ \\
\hline 1903/01/04 05:07 & 8.0 Tonga & $-79(\mathrm{~T})$ \\
\hline 1903/08/11 04:32 & 8.3 Southern Greece & $+56(\mathrm{P})$ \\
\hline 1905/07/09 09:40 & 8.4 Mongolia & $+37(\mathrm{P})$ \\
\hline 1905/07/23 02:46 & 8.4 Central Mongolia & $+23(\mathrm{P})$ \\
\hline $1906 / 01 / 31 \quad 15: 36$ & 8.8 Colombia-Ecuador & $+9(\mathrm{~T})$ \\
\hline 1906/08/17 00:40 & 8.2 Valparaiso, Chile & $-13(\mathrm{~T})$ \\
\hline 1907/10/21 04:23 & 8.0 Afghanistan & $-88(\mathrm{P})$ \\
\hline 1908/12/12 12:08 & 8.2 off the Coast of Central Peru & $-5(\mathrm{PU}-\mathrm{T})$ \\
\hline 1911/06/15 14:26 & 8.1 Ryukyu Islands, Japan & $-33(\mathrm{PU})$ \\
\hline $1914 / 05 / 2614: 22$ & 8.0 West New Guinea & $-75(\mathrm{P})$ \\
\hline 1915/05/01 05:00 & 8.0 Kurile Islands & $-61(\mathrm{PU})$ \\
\hline 1917/05/01 18:26 & 8.0 Kermadec Islands, New Zealand & $+64(\mathrm{~T})$ \\
\hline 1917/06/26 05:49 & 8.4 Tonga & $+8(\mathrm{~T})$ \\
\hline 1918/08/15 12:18 & 8.0 Celebes Sea & $-52(\mathrm{P})$ \\
\hline 1918/09/07 17:16 & 8.2 Kuril Islands & $-75(\mathrm{P})$ \\
\hline 1919/04/30 07:17 & 8.2 Tonga Region & $+15(\mathrm{PU})$ \\
\hline 1920/06/05 04:21 & 8.0 Taiwan Region & $-33(\mathrm{~T})$ \\
\hline 1920/09/20 14:39 & 8.0 Loyalty Islands & $+37(\mathrm{~T})$ \\
\hline 1922/11/11 04:32 & 8.5 Chile-Argentina Border & $-36(\mathrm{PU})$ \\
\hline $1923 / 02 / 0316: 01$ & 8.5 Kamchatka & $+28(\mathrm{P})$ \\
\hline $1924 / 04 / 1416: 20$ & 8.3 Mindanao, Philippines & $-54(\mathrm{~T})$ \\
\hline 1928/06/17 03:19 & 8.0 Oaxaca, Mexico & $-14(\mathrm{~T})$ \\
\hline 1931/08/10 21:18 & 8.0 northern Xinjiang, China & $+47(\mathrm{~T})$ \\
\hline 1932/06/03 10:36 & 8.1 Jalisco, Mexico & $-73(\mathrm{P})$ \\
\hline 1933/03/02 17:31 & 8.4 Sanriku, Japan & $+10(\mathrm{PU})$ \\
\hline 1934/01/15 08:43 & 8.1 Bihar, India & $+15(\mathrm{P})$ \\
\hline 1938/02/01 19:04 & 8.5 Banda Sea & $-75(\mathrm{P})$ \\
\hline 1938/11/10 20:18 & 8.2 Shumagin Islands, Alaska & $-3(\mathrm{~T})$ \\
\hline 1939/04/30 02:55 & 8.0 Solomon Islands & $+3(\mathrm{~T})$ \\
\hline $1940 / 05 / 2416: 33$ & 8.2 near the Coast of Central Peru & $-32(\mathrm{PU})$ \\
\hline 1941/11/25 18:03 & 8.2 Azores-Cape St.Vincent Ridge & $-81(\mathrm{P})$ \\
\hline $1942 / 08 / 2422: 50$ & 8.2 Off the Coast of Central Peru & $+2(\mathrm{~T})$ \\
\hline 1943/04/06 16:07 & 8.2 off the Coast of Coquimbo, Chile & $-45(\mathrm{P})$ \\
\hline 1944/12/07 04:35 & 8.1 Tonankai, Japan & $+22(\mathrm{PU}-\mathrm{T})$ \\
\hline 1945/11/27 21:57 & 8.0 off the Coast of Pakistan & $+22(\mathrm{~T})$ \\
\hline 1946/04/01 12:28 & 8.1 Unimak Islands, Alaska & $+74(\mathrm{~T})$ \\
\hline 1946/08/04 17:51 & 8.0 Dominican Republic & $-51(\mathrm{~T})$ \\
\hline 1946/12/20 19:19 & 8.1 Nankaido, Japan & $-12(\mathrm{~T})$ \\
\hline 1948/01/24 17:46 & 8.2 Panay, Philippines & $-57(\mathrm{PU})$ \\
\hline 1949/08/22 04:01 & 8.1 Queen Charlotte Island, B.C., Canada & $+46(\mathrm{~T})$ \\
\hline 1950/08/15 14:09 & 8.6 Assam-Tibet & $+42(\mathrm{~T})$ \\
\hline 1952/03/04 01:22 & 8.1 Hokkaido, Japan Region & $-22(\mathrm{P})$ \\
\hline 1952/11/04 16:58 & 9.0 Kamchatka, Russia & $+86(\mathrm{~T})$ \\
\hline 1957/03/09 14:22 & 8.6 Andreanof Islands, Alaska & $+65(\mathrm{~T})$ \\
\hline 1957/12/04 03:37 & 8.1 Gobi-Altai, Mongolia & $-27(\mathrm{~T})$ \\
\hline 1958/11/06 22:58 & 8.3 Kuril Islands & $-10(\mathrm{PU})$ \\
\hline 1959/05/04 07:15 & 8.2 near the East Coast of Kamchatka & $-41(\mathrm{P})$ \\
\hline 1960/05/22 19:11 & 9.5 Chile & $-70(\mathrm{~T})$ \\
\hline 1963/10/13 05:17 & 8.5 Kuril Islands & $+78(\mathrm{~T})$ \\
\hline 1964/03/28 03:36 & 9.2 Prince William Sound, Alaska & $-89(\mathrm{~T})$ \\
\hline 1965/02/04 05:01 & 8.7 Rat Islands, Alaska & $-47(\mathrm{~T})$ \\
\hline 1966/10/17 21:41 & 8.1 near the Coast of Central Peru & $+12(\mathrm{PU})$ \\
\hline 1968/05/16 00:49 & 8.2 off the East Coast of Honshu, Japan & $-33(\mathrm{~T})$ \\
\hline 1969/08/11 21:27 & 8.2 Kuril Islands & $+16(\mathrm{~T})$ \\
\hline
\end{tabular}




\begin{tabular}{|c|c|c|}
\hline Date in UTC - Time & Magnitude (Region) & Time Lapse from Syzygy Events \pm Days \\
\hline 1970/07/31 17:08 & 8.0 Colombia & $+17(\mathrm{P})$ \\
\hline 1971/01/10 07:17 & 8.1 Papua, Indonesia & $+31(\mathrm{~T})$ \\
\hline 1974/10/03 14:21 & 8.1 near the Coast of Central Peru & $+57(\mathrm{~T})$ \\
\hline 1976/08/16 16:11 & 8.0 Mindanao, Philippines & $+82(\mathrm{PU})$ \\
\hline 1977/06/22 12:08 & 8.1 Tonga Region & $-79(\mathrm{P})$ \\
\hline 1977/08/19 06:08 & 8.3 South of Sumbawa, Indonesia & $+39(\mathrm{PU})$ \\
\hline 1979/12/12 07:59 & 8.1 near the Coast of Ecuador & $+80(\mathrm{PU})$ \\
\hline 1985/03/03 22:47 & 8.0 Offshore Valparaiso, Chile & $+62(\mathrm{~T})$ \\
\hline 1985/09/19 13:17 & 8.0 Michoacan, Mexico & $+39(\mathrm{~T})$ \\
\hline 1986/05/07 22:47 & 8.0 Andreanof Islands, Aleutian Islands, Alaska & $-13(\mathrm{~T})$ \\
\hline $1989 / 05 / 2310: 54$ & 8.1 Macquarie Island Region & $+86(\mathrm{~T})$ \\
\hline 1994/06/09 00:33 & 8.2 La Paz, Bolivia & $-15(\mathrm{P})$ \\
\hline 1994/10/04 13:22 & 8.3 Kuril Islands & $+45(\mathrm{PU})$ \\
\hline 1995/07/30 05:11 & 8.0 Near Coast of Northern Chile & $+70(\mathrm{PU})$ \\
\hline 1995/10/09 15:35 & 8.0 Near Coast of Jalisco, Mexico & $-1(\mathrm{PU})$ \\
\hline 1996/02/17 05:59 & 8.2 Irian Jaya Region, Indonesia & $+47(\mathrm{~T})$ \\
\hline 1998/03/25 03:12 & 8.1 Balleny Islands Region & -12 (PU) \\
\hline 2000/11/16 04:54 & 8.0 New Ireland Region, Papua New Guinea & $+54(\mathrm{~T})$ \\
\hline 2001/06/23 20:33 & 8.4 near the coast of Southern Peru & $+12(\mathrm{P})$ \\
\hline 2003/09/25 19:50 & 8.3 Hokkaido, Japan Region & $+45(\mathrm{~T})$ \\
\hline 2004/12/23 14:59 & 8.1 North of Macquarie Island & $-56(\mathrm{~T})$ \\
\hline 2004/12/26 00:58 & 9.1 off the West Coast of Northern Sumatra & $-59(\mathrm{~T})$ \\
\hline 2005/03/28 16:09 & 8.6 Northern Sumatra, Indonesia & $+27(\mathrm{PU})$ \\
\hline 2006/05/03 15:26 & 8.0 Tonga & $-50(\mathrm{PU}-\mathrm{T})$ \\
\hline 2006/11/15 11:14 & 8.3 Kuril Islands & $-69(\mathrm{P})$ \\
\hline 2007/01/13 04:23:21 & 8.1 East of the Kuril Islands & $+49(\mathrm{~T})$ \\
\hline 2007/04/01 20:39:58 & 8.1 Solomon Islands & $-29(\mathrm{~T})$ \\
\hline 2007/08/15 23:40:57 & 8.0 near the Coast of Central Peru & $+13(\mathrm{~T})$ \\
\hline 2007/09/12 11:10:26 & 8.5 Southern Sumatra, Indonesia & $-15(\mathrm{~T})$ \\
\hline 2009/09/29 17:48:10 & 8.1 Samoa Islands Region & $-54(\mathrm{PU})$ \\
\hline 2010/02/27 06:34:14 & 8.8 Offshore Maule, Chile & $-58(\mathrm{PU})$ \\
\hline 2011/03/11 05:46:23 & 9.0 near the East Coast of Honshu, Japan & $-80(\mathrm{~T})$ \\
\hline 2012/04/11 08:38:37 & 8.6 off the West Coast of Northern Sumatra & $+54(\mathrm{P})$ \\
\hline 2012/04/11 10:43:09 & 8.2 off the West Coast of Northern Sumatra & $+54(\mathrm{P})$ \\
\hline
\end{tabular}

PU - Penumbral Eclipse, P - Partial Eclipse, T - Total Eclipse

\section{References}

[1] Perry, R.H. and Green, D.W.: Perry's Chemical Engineers' Handbook, $8^{\text {th }}$ Edition, (McGraw-Hill, 2007).

[2] Seidelmann, P. K. (ed.): Explanatory Supplement to the Astronomical Almanac, ISBN 0-935702-68-7, (University Science Books, CA, 1992).

[3] Meeus J.: Astronmical Algorithms, $2^{\text {nd }}$ Edition, (WillmannBell, 1999).

[4] Australian Bureau of Meteorology: South Pacific Sea Level and Climate Monitoring Project, Hourly Sea Level and Meteorological Data, (Internet: http://www.bom.gov.au/oceanography/projects/spslcmp/data/i ndex.shtml, 2015).

[5] U.S. Geological Survey at Page URL (2015): http://earthquake.usgs.gov/earthquakes/eqarchives/year/mag8/ magnitude8_1900_date.php [6] Moon
http://eclipse.gsfc.nasa.gov/5MCLE/5MCLE-Figs-10.pdf

[7] Bates, A.: Galilean Moons, Kepler's Third Law, and the Mass of Jupiter, Phys. Teach. 51, 428 (2013).

[8] Eisenstaedt, J.: From Newton to Einstein: A forgotten relativistic optics of moving bodies, Am. J. Phys. 75, 741 (2007).

[9] McCall, M.: Gravitational orbits in one dimension, Am. J. Phys. 74, 1115 (2006).

[10] Hussain, Z.: On Newton's Law of Attractions, Am. J. Phys. 19, $146(1951)$.

[11] Noordeh, E., Hall, P. and Cuk, M.: Simulating the Phases of the Moon Shortly After Its Formation, Phys. Teach. 52, 239 (2014). 